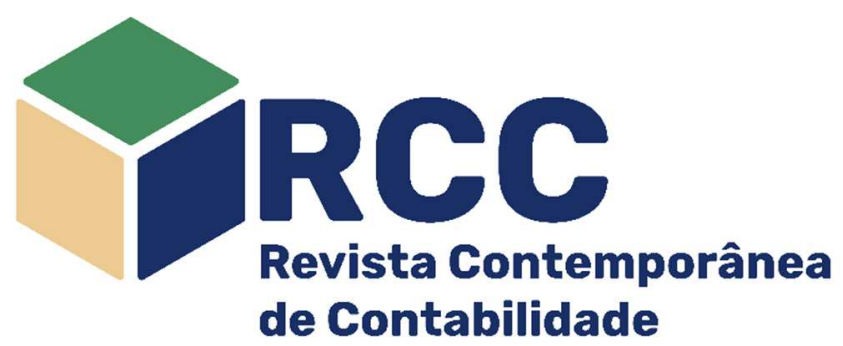

\title{
Open-book accounting no relacionamento entre comprador e fornecedor no setor agroindustrial
}

\author{
Open-book accounting in the buyer and supplier relationship in the agro-industrial sector

\section{Open-book accounting en la relación entre comprador y proveedor en el sector agroindustrial}

\author{
Anderson Martins Cardoso \\ Mestre em Contabilidade e Controladoria (UFU) \\ Servidor da Prefeitura Municipal de Uberlândia/MG, Brasil \\ andersonmar@yahoo.com.br \\ https://orcid.org/0000-0003-4162-8104 (])
}

Rosimeire Pimentel Gonzaga Doutora em Controladoria e Contabilidade pela FEA (USP) Professora Adjunta do Departamento de Ciências Contábeis e do Programa de Pós-Graduação em Ciências Contábeis (UFES), Vitória/ES, Brasil ropgonzaga@gmail.com https://orcid.org/0000-0003-4889-1482 (0)
Lara Cristina Francisco de Almeida Fehr ${ }^{*}$ Doutora em Controladoria e Contabilidade pela FEA (USP) Professora Adjunta do Curso de Ciências Contábeis e do Programa de Pós-Graduação em Ciências Contábeis (UFU), Uberlândia/MG, Brasil larafehr@ufu.br https://orcid.org/0000-0001-9991-2613 (i)

Sérgio Lemos Duarte Doutor em Controladoria e Contabilidade pela FEA (USP) Professor Adjunto do Curso de Ciências Contábeis e do Programa de Pós-Graduação em Ciências Contábeis (UFU)

Uberlândia/MG, Brasil sergiold@ufu.br

https://orcid.org/0000-0002-8725-1552

Endereço do contato principal para correspondência Av Geraldo Abrão, 611, Bairro Jardim Inconfidência, CEP: 38411-229 - Uberlândia/MG, Brasil

\section{Resumo}

Objetivou-se identificar como o OBA (Open-Book Accounting) é praticado no relacionamento entre uma empresa agroindustrial e um de seus fornecedores diretos, na perspectiva da ECT (Economia dos Custos de Transação). Trata-se de estudo de caso único e díade. Empregaram-se entrevistas semiestruturadas, análise documental e observação direta para coleta dos dados e análise de conteúdo para análise. Verificou-se que o OBA é aplicado bilateralmente, com detalhamento amplo de informações pelo fornecedor, e estreito e eventual pela compradora. Sua aplicação não foi imposta e emergiu pela confiança e benefícios mútuos estabelecidos, ampliação de negócios conjuntos e contrato exclusivo de fornecimento. No caso específico da empresa compradora, o propósito principal do OBA é apoiar o TCO (Total Cost of Ownership), empregado para seleção e (re)negociação com fornecedores. Conclui-se que o compartilhamento consensual de informações, prevendo benefícios mútuos, aumenta a disposição ao OBA e as chances de identificação de oportunidades de redução de custos.

Palavras-chave: Gestão de Custos Interorganizacionais; Open-book Accounting; Economia dos Custos de Transação; Agroindústria

\section{Abstract}

The objective of this research was to identify how the OBA (Open-Book Accounting) is practiced in the relationship between an agroindustrial company and one of its direct suppliers, from the TCE (Transaction Cost Economics) perspective. This is a unique case study, employing a dyad approach. For data collection, semi-structured interviews, document analysis and direct observation were used. Data analysis was performed through content analysis. The results evidenced that the OBA is applied bilaterally, with a high level of detailing information by the supplier, and eventually at a low level of detail from the buyer. The process of sharing information through the OBA emerged from the moment the trust, benefit forecasting, opportunities for joint business expansion and exclusive supply contract were established. The main application of the OBA is to support the TCO (Total Cost of Ownership) used for the selection and (re)negotiation with the. It was concluded that the usage of the OBA increases the amount of consensual information sharing and also the chances of identifying opportunities of cost reduction.

Keywords: Management of Interorganizational Costs; Open-book Accounting; Transaction Cost Economics; Agro-industry 


\section{Resumen}

Esta investigación objetivó identificar cómo el OBA (Open-Book Accounting) es practicado entre una empresa agroindustrial y uno de sus proveedores directos, en la perspectiva de la ECT (Economía de los Costos de Transacción). Se trata de un estudio de caso único, desde el enfoque de la deuda. Se emplearon entrevistas semiestructuradas, análisis documental y observación directa para la recolección de datos y el análisis de contenido para el análisis. Se verificó que el OBA se aplica bilateralmente, con informaciones ampliamente detalladas por el proveedor, y estrecha y eventual por la compradora. Su aplicación no fue impuesta y surgió por la confianza establecida, previsión de beneficios, oportunidades de ampliación de negocios conjuntos y contrato exclusivo de suministro. El propósito principal de la aplicación del OBA es apoyar al TCO (Costo total de propiedad), empleado para selección y (re)negociación con proveedores. Se concluyó que el compartir consensuado de informaciones, previendo beneficios mutuos, aumenta la disposición al uso del OBA y las posibilidades de identificación de oportunidades de reducción de costos.

Palabras clave: Gestión de Costos Interorganizacionales, Economía de los Costos de Transacción; Agroindustrial

\section{Introdução}

O ambiente de negócios tem vivido transformações na tentativa de acompanhar a evolução da sociedade e dos meios de produção capitalista, ultrapassando os limites definidos pela teoria econômica clássica (ZYLBERSZTAJN; SZTAJN, 2005). Nesse sentido, as relações interorganizacionais entre parceiros de negócios têm se tornado mais frequentes, principalmente a partir dos anos 90, quando novas teorias institucionais e organizacionais começaram a ser largamente difundidas no ambiente corporativo (PECl, 1999).

Percebida essa tendência, começou-se a considerar a importância de estender o domínio da Contabilidade de Custos, para além das fronteiras da empresa. É nesse cenário que se insere a Gestão de Custos Interorganizacionais $(\mathrm{GCl})$, cujo um dos objetivos é viabilizar a troca de informações para a otimização dos custos e o gerenciamento das atividades ao longo da cadeia de valor (AGNDAL; NILSSON, 2009), e o Open-book Accounting (OBA), que é o processo de compartilhamento de informações relativas a custos, processos e/ou atividades, entre partes em um relacionamento (FEHR; ROCHA, 2018).

A aplicação do OBA ocorre no contexto da $\mathrm{GCl}$ porque sua operacionalização requer o emprego de um instrumento de gestão de custos que permita a otimização dos custos interorganizacionais e a criação e/ou manutenção de vantagem competitiva (CAMACHO et al., 2014). O compartilhamento de informações entre empresas serve para demonstrar comprometimento no relacionamento, fortalecer posição entre concorrentes enquanto compradora ou fornecedora, entender as operações da outra empresa, empenhar-se para otimização dos custos, etc. (KULMALA, 2002; KAJÜTER; KULMALA, 2005).

No entanto, Agndal e Nilsson (2010) verificaram que, na prática, o OBA é um processo muitas vezes unilateral, no sentido do fornecedor para o comprador. As informações recebidas pelo comprador podem ser usadas para adquirir conhecimento sobre processos e conduzir atividades conjuntas com parceiros, já que a abertura de informações permite ao comprador apoiar o fornecedor na identificação de áreas críticas (AGNDAL; NILSSON, 2008). Porém, as informações compartilhadas por vezes são usadas para forçar os fornecedores a reduzirem os preços praticados (KAJÜTER; KULMALA, 2005), revelando o comportamento oportunista do comprador (FEHR; ROCHA, 2018). Essa situação pode comprometer a aplicação do OBA e afetar negativamente o relacionamento comprador-fornecedor.

Com base nos fundamentos da Economia dos Custos de Transação (ECT), pode-se afirmar que, de um lado, o compartilhamento de informações de custos possui potencial para aumentar a eficiência da transação por meio da redução de custos. Mas, de outro lado, o OBA unilateral, ao possibilitar o comportamento oportunista dos compradores, devido à assimetria informacional, aumenta os riscos no relacionamento e, consequentemente, os custos de transação (WILLIAMSON, 1985), principalmente os de monitoramento (WINDOLPH; MOELLER, 2012), tornando-se necessário o estabelecimento de salvaguardas.

Para a ECT, a assimetria de informação afeta negativamente a transação e está relacionada com o comportamento oportunista das partes, a incerteza relativa à transação, a frequência de ocorrência da transação, a especificidade dos ativos investidos, a complexidade dos contratos, a racionalidade limitada dos agentes e à necessidade de mecanismos de governança (WILLIAMSON, 1996). Os fatores preconizados pela ECT apresentam-se, também, como potenciais influenciadores da aplicação do OBA e do relacionamento desenvolvido entre comprador e fornecedor. Desse modo, a presente pesquisa pode contribuir ao corroborar essa teoria.

Pesquisas têm investigado se as empresas estão adotando políticas de OBA para melhorar o desempenho tanto de compradores quanto de fornecedores (KAJÜTER; KULMALA, 2005; KUMRA; AGNDAL; NILSSON, 2012; GRAFTON; MUNDY, 2017; KOURTI, 2017; FEHR; ROCHA, 2018; LATUSEK; VLAAR, 2018; CAGLIO, 2018), aumentar a eficiência da cadeia de suprimentos e, por conseguinte, reduzir os custos de transação e operação. A aplicação do OBA unilateral pode ser explicada, em certa medida, pelo fato de o comprador possuir, geralmente, maior poder sobre o fornecedor, tornando evidente a questão do desequilíbrio de poder nesses relacionamentos (KULMALA, 2004). 
Porém, há indicações de que a prática bem-sucedida do OBA requer, entre outros, equilíbrio de poder entre comprador e fornecedor, estabelecimento e/ou aumento do volume de negócios mútuos, confiança e fortalecimento do princípio do "ganha-ganha" (KULMALA, 2004; KAJÜTER; KULMALA, 2005; CAGLIO; DITILLO, 2012). Nessa perspectiva, a forma como o OBA é praticado (unilateral ou bilateralmente, por imposição ou não, com estabelecimento de salvaguardas, de benefícios mútuos, com perspectiva de longo prazo, etc.) acaba por influenciar o relacionamento construído entre comprador-fornecedor (KAJÜTER; KULMALA 2005; AGNDAL; NILSSON, 2010; WINDOLPH; MOELLER 2012).

Pesquisaram-se, neste estudo, duas empresas multinacionais da agroindústria, uma compradora e outra fornecedora. A escolha do setor se justifica por ser segmento de importância econômica significativa em termos mundiais, e no Brasil vem apresentando lucros e tendências constantes de crescimento, além do aumento no seu nível de concentração, resultado de aquisições e fusões entre os agentes intermediários (traders) (BASTOS; ARAÚJO, 2017). A agroindústria transforma o produto in natura e o comercializa pronto para o consumo, implicando uma complexa e sistêmica organização de atividades e o apoio de diferentes setores, o que envolve gestão eficiente e competitiva (ZIBETTI; BARROSO, 2009), inclusive a gestão e a análise de custos interorganizacionais.

Diante o exposto, considerando-se a relevância econômica da agroindústria, a importância de uma gestão estratégica de custos, especialmente em relacionamentos interorganizacionais, e a consequente necessidade de compartilhamento de informações, formulou-se a seguinte questão de pesquisa: como é praticado o OBA entre uma empresa agroindustrial e um de seus fornecedores diretos? Pretendeu-se identificar como o OBA é praticado no relacionamento entre uma empresa agroindustrial e um de seus fornecedores diretos, na perspectiva da ECT. A presente pesquisa foi desenvolvida, abordando uma díade, ou seja, tanto o comprador quanto o fornecedor foram pesquisados.

Como resultado dos objetivos estabelecidos, buscou-se contribuir para a compreensão do relacionamento entre comprador do setor agroindustrial e um de seus fornecedores de primeiro nível. Ainda, dentre as contribuições deste estudo, espera-se, de modo geral, que os resultados encontrados auxiliem no entendimento das dificuldades para aplicação do OBA nas empresas. Espera-se também contribuir com gestores do segmento agroindustrial diante a possibilidade de verificar os fatores que interferem na aplicação do OBA e nos seus potenciais resultados, auxiliando na detecção e resolução de problemas relacionados à aplicação dessa ferramenta. Para a academia, espera-se que este estudo possa auxiliar pesquisas futuras sobre a prática do OBA no setor estudado, ampliando o escopo de investigação e indicando caminhos para o aperfeiçoamento do processo de compartilhamento de informações.

\section{Fundamentação Teórica}

\subsection{Gestão Estratégica de Custos e GCl}

Tradicionalmente, o termo Gestão Estratégica de Custos (GEC) é utilizado para designar a conexão entre a gestão de custos e a gestão estratégica da organização (HANSEN; MOWEN, 2010; SOUZA; HEINEN, 2012; ANDRADE et al., 2013). Shank e Govindarajan (1997) categorizaram a GEC com base em três estratégias gerais, quais sejam: i) análise da cadeia de valor; ii) análise do posicionamento estratégico; e iii) análise dos direcionadores ou determinantes de custos.

Para Shank e Govindarajan (1997) a cadeia de valor pode ser definida como o conjunto de atividades criadoras de valor que se inicia com as fontes mais básicas, ou seja, na origem da matéria-prima, passa pelos fornecedores de insumos e termina no momento da entrega do produto final ao consumidor.

O conceito de cadeia de valor foi sendo construído no decorrer do desenvolvimento de novas pesquisas. A partir de Shank e Govindarajan (1997), os pesquisadores Rocha e Borinelli (2007) incluíram no espectro da cadeia de valor o setor de serviços (não apenas a indústria) e as atividades de pós-venda. Por fim, Duarte (2017) incluiu, na definição, os agentes que participam da cadeia e seus relacionamentos, sendo este o conceito usado neste estudo.

A análise da cadeia de valor consiste, portanto, na identificação e exploração de ligações internas (cadeia de valor interna) e externas (cadeia de valor externa) da empresa, com o objetivo de fortalecer a posição estratégica escolhida. Para Hansen e Mowen (2010), esta exploração de ligações depende da identificação das atividades e da seleção daquelas que podem ser usadas para produzir ou sustentar uma vantagem competitiva e, em seguida, de uma análise sobre como custos e outros fatores não financeiros variam com a consideração de diferentes grupos de atividades (ROCHA; BORINELLI, 2007).

Já para a análise do posicionamento estratégico, Porter (1989; 1991) propôs uma tipologia composta por três estratégias genéricas que podem ser adotadas por uma organização: i) liderança no custo total; ii) diferenciação e iii) enfoque, conforme exposto no Quadro 1. Para Hansen e Mowen (2010), o posicionamento estratégico seria o processo de seleção de uma combinação ótima das três abordagens estratégicas genéricas de Porter (1991). 


\section{Quadro 1 - Estratégias Genéricas para Análise do Posicionamento Estratégico}

\begin{tabular}{|c|c|}
\hline 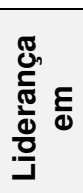 & $\begin{array}{l}\text { O objetivo dessa estratégia é oferecer um valor melhor ou igual aos clientes a um custo menor do que } \\
\text { aquele oferecido pelos competidores. Assim, uma estratégia de baixo custo aumenta o valor para o cliente } \\
\text { ao minimizar o sacrifício dele. Por exemplo: uma empresa pode reprojetar um produto (análise da cadeia } \\
\text { de valor e ciclo de vida do produto) de forma que poucas peças sejam necessárias, reduzindo os custos } \\
\text { de produção e de manutenção do produto após a compra (custo total para os consumidores). }\end{array}$ \\
\hline 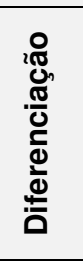 & $\begin{array}{l}\text { Busca aumentar o valor ao cliente ao aumentar o que ele recebe (realização do cliente). Uma vantagem } \\
\text { competitiva é criada ao oferecer algo para o cliente que não é oferecido pelos competidores. Assim, é } \\
\text { preciso criar características de produto que o destaque dos produtos competidores. Tais diferenças } \\
\text { podem ser funcionais, estéticas ou estilísticas (ex.: produtor de bolachas que fabrica em formatos de } \\
\text { animais ou personagens de desenhos infantis). No entanto, para ter algum valor, os clientes precisam } \\
\text { ver essas variações como importantes; além do mais, é preciso que o valor adicionado para o cliente pela } \\
\text { diferenciação exceda os custos da empresa para oferecê-la. }\end{array}$ \\
\hline 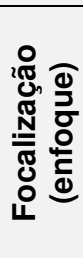 & $\begin{array}{l}\text { Essa estratégia envolve selecionar, ou enfatizar, um conjunto de clientes ou segmentos de mercado no } \\
\text { qual competir. Uma possibilidade é selecionar os mercados e clientes que pareçam mais atraentes e } \\
\text { depois desenvolver as capacidades para atender esses segmentos-alvo. Outra possibilidade é selecionar } \\
\text { segmentos específicos em que as competências essenciais da empresa sejam superiores às dos } \\
\text { competidores. Uma estratégia de focalização reconhece que nem todos os segmentos (clientes e regiões } \\
\text { geográficas, por exemplo) são os mesmos. Dadas as capacidades diferenciadoras e as capacidades } \\
\text { potenciais da organização, alguns segmentos são mais atraentes do que outros. }\end{array}$ \\
\hline
\end{tabular}
Fonte: adaptado de Porter (1991) e Hansen; Mowen (2010).

Por fim, ensejando a análise dos direcionadores de custos, Shank e Govindarajan (1997) relatam que os direcionadores/determinantes estratégicos de custos diferem dos direcionadores de custos da contabilidade tradicional, em que basicamente o volume de produção é considerado como a única causa da variação dos custos da empresa. Asseveram os autores que explicar o comportamento dos custos com base em apenas um direcionador é algo limitado, e que outros fatores (além do volume, p. ex.) também interferem no direcionamento dos custos de produção das empresas. Logo, cada organização deve descobrir quais são os seus principais elementos causadores de custos e, desta forma, discutir as estratégias mais apropriadas em função da sua estrutura de custos (HANSEN; MOWEN, 2010).

Informações de custos sobre clientes, fornecedores e projetos de produtos diferentes, por exemplo, também são necessários para apoiar os objetivos da gestão estratégica, e o conjunto de informações também precisa ser prospectivo e fornecer discernimentos sobre períodos e atividades futuras (SOUZA; HEINEN, 2012). Portanto, a análise da cadeia de valor pode produzir mudanças organizacionais que fundamentalmente alteram a natureza e a demanda por informações de custos (HANSEN; MOWEN, 2010).

Pode-se dizer, então, que a GEC consiste no uso de dados de custos para desenvolver e identificar estratégias superiores que produzirão uma vantagem competitiva sustentável, entendendo-se esta como a criação de um valor melhor para o cliente por um custo igual, ou mais baixo, do que aquele oferecido pelos competidores, ou a criação de um valor equivalente por um custo menor do que aquele oferecido pelos competidores (DAY; REIBSTEIN, 1999; KOTLER; ARMSTRONG, 1999; GUILDING; CRAVENS; TAYLES, 2000).

A literatura apresenta várias práticas de GEC, a exemplo de custeio-alvo, custeio por ciclo de vida, análise de custos de concorrentes, custo total para consumidores, análise da cadeia de valor, gestão de custos interorganizacionais, etc. (ANSARI, 1997; ELLRAM; SIFERD, 1998; ROCHA; BORINELLI, 2007; SOUZA; ROCHA 2008; SOUZA; ROCHA, 2009; SANTOS; ROCHA, 2011; FEHR; ROCHA, 2018; ZHANG et al., 2017). Considerando especificamente a $\mathrm{GCl}$, esta é um instrumento que procura viabilizar as alianças interorganizacionais (COOPER; SLAGMULDER, 1999; 2004).

Nesse sentido, a GCI representa um instrumento da GEC focado na otimização dos custos, processos e atividades, criando vantagens competitivas frente às cadeias concorrentes. É, portanto, um instrumento capaz de gerar benefícios a toda a cadeia, e deve ser incluído no planejamento e na gestão estratégica das empresas (COOPER; YOSHIKAWA, 1994).

Com as empresas terceirizando uma alta porcentagem do valor agregado de seus produtos, seu sucesso se torna cada vez mais dependente da eficiência de suas redes de suprimentos (KULMALA; PARANKO; UUSI-RAUVA, 2002; COOPER; SLAGMULDER, 2004). Consequentemente, o escopo da gestão de custos foi ampliado para além dos limites da firma única (KULMALA, 2002, 2004). Na atual conjuntura, não é satisfatório para uma organização ser eficiente apenas na gestão interna de custos, despontando a necessidade de inserir-se em uma cadeia de valor que seja eficiente (COOPER; SLAGMULDER, 2004).

Para tanto, a condição básica para a implementação da GCl é compartilhar informações de custos, sendo o OBA uma ferramenta importante para atingir esse objetivo (DI; WANG, 2017). Cooper e Slagmulder (1999) também corroboram a ideia de que a GCl visa a um comportamento coordenado entre compradores e fornecedores para otimização dos custos, o que a tem tornado uma área de pesquisa de gestão de custos independente.

Para os propósitos desta pesquisa, são discutidas algumas das principais características das dimensões que compõem a $\mathrm{GCl}$ : produtos (margem e funcionalidade), componentes (índice de valor e 
restrição tecnológica), tipos de cadeia (tirania, oligarquia, democracia), mecanismos (disciplinadores, capacitores e incentivadores) e níveis de relacionamento (auxiliar, comum, familiar e principal). A Figura 1, na sequência, apresenta o modelo conceitual de análise da GCI. Para Souza e Rocha (2008), esse modelo representa um conjunto de possibilidades que podem auxiliar os gestores na tomada de decisões.

Em relação ao produto, faz-se necessário identificar qual tipo é recomendado à aplicação da $\mathrm{GCl}$, destacando-se duas características relevantes: a margem e a funcionalidade. Produtos com margem muito baixa apresentam maior necessidade de uma gestão de custos, ampliando a possibilidade da prática da GCl. Assim como a margem, a funcionalidade de um produto influencia decisivamente a aplicação da GCI (SOUZA; ROCHA, 2008).

Figura 1 - Modelo conceitual de análise da aplicação da GCI

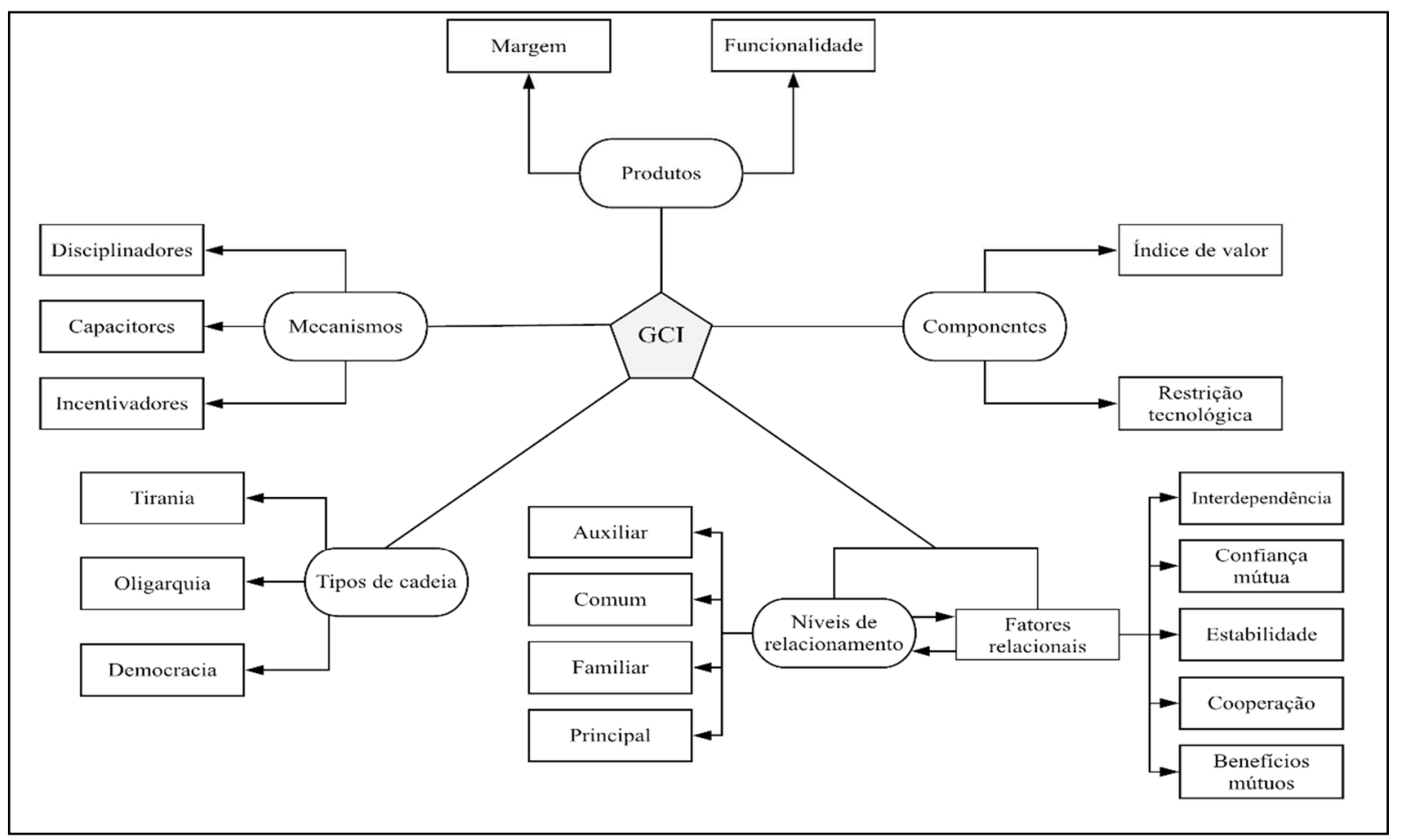

Fonte: Desenvolvido a partir de Cooper e Slagmulder (1999), Souza e Rocha (2008) e Duarte (2017).

Na visão de Cooper e Slagmulder (1999), o nível de funcionalidade está relacionado à quantidade de especificações do produto. Quanto maiores as funcionalidades (propriedades e atributos) de um produto, maior é o campo de possibilidade de gerenciamento de custos além das fronteiras de uma empresa (SOUZA; ROCHA, 2008). Neste campo, a GCl pode propiciar um gerenciamento adequado e redução dos custos (KAJÜTER; KULMALA, 2005).

Quanto aos componentes de um produto, não é necessária a aplicação da $\mathrm{GCl}$ a todos eles. Sua aplicação deve estar voltada aos principais componentes, objetivando identificar quais devem ser observados. Para tanto, a empresa precisa considerar duas características importantes: restrição tecnológica e índice de valor (COOPER; SLAGMULDER, 1999).

O índice de valor é uma análise que relaciona custo com grau de importância do custo, sendo que quanto menor o índice de valor, maior o seu custo, possibilitando uma maior necessidade de aplicação da GCI. Da restrição tecnológica, a análise recai sobre sua importância para a organização, porque se for estratégica deve ser mantida restrita, não devendo ser cedida a terceiros; se contrário, é possível estruturar parcerias para pesquisa e desenvolvimento (COOPER; SLAGMULDER, 1999). Souza e Rocha (2009) argumentam que a margem de lucro, as restrições tecnológicas e o índice de valor, como fatores condicionantes, podem fomentar ou desestimular a prática da GCl.

O relacionamento entre os membros da cadeia, por sua vez, segundo Cooper e Slagmulder (1999), pode ser entendido em quatro níveis: comum, auxiliar, principal e familiar. A relação comum é fraca e com baixa dependência; já o relacionamento do tipo auxiliar apresenta um pouco de dependência e pela especificação do produto, o relacionamento estreita-se um pouco mais, gerando uma maior estabilidade na manutenção de fornecedores (COOPER; SLAGMULDER, 1999).

O relacionamento com fornecedores do tipo principal apresenta uma relação mais integrada com a empresa, e o grau de estabilidade, confiança e a distribuição de benefícios entre as empresas são muito maiores, pois compartilham conhecimento já no desenvolvimento do produto (COOPER; SLAGMULDER, 1999). Já o tipo familiar apresenta o maior nível de interdependência porque o fornecedor atua diretamente na empresa, compartilhando, muitas vezes, informações, tecnologias e até mesmo funcionários, onde o 
responsável pelo projeto do produto ou dos componentes geralmente é dividido com o fornecedor (COOPER; SLAGMULDER, 1999; KAJUTER; KULMALA, 2005).

$\mathrm{Na}$ visão de Cooper e Slagmulder (1999), esse tipo de relacionamento estimula pesquisas desde o primeiro estágio do ciclo de vida do produto voltadas para o aperfeiçoamento do mesmo. Quanto maior o nível de relacionamento existente entre as empresas, maior será a possibilidade de implantação integral da GCl.

Com relação ao tipo de cadeia, Cooper e Slagmulder (1999) identificam três óticas: tirania, oligarquia e democracia. Essa divisão é estabelecida com base no número de empresas que dominam a cadeia. $\mathrm{Na}$ estrutura do tipo tirania, uma única empresa domina e determina como as relações devem ocorrer e estabelece as funções de cada um dos envolvidos; na oligárquica, o poder é distribuído entre duas ou mais empresas, ocorrendo assim, uma separação visível entre as empresas dominadoras e as demais e na democracia, não existe uma empresa ou grupo de empresas dominando, sendo os acordos estabelecidos mutuamente.

Em relação aos mecanismos: disciplinadores, capacitores e incentivadores, na visão de Souza e Rocha (2009), estes são auxiliares na gestão de custos com o objetivo de orientar, controlar, medir, informar e dar parâmetros, tornando possível a aplicação da GCl. Cooper e Slagmulder (1999) comentam que o propósito desses mecanismos é transmitir pressão quanto à gestão de custo a toda a cadeia, para maximizar o retorno aos seus membros.

Os disciplinadores são mecanismos capazes de regular as ações interorganizacionais e deve ser utilizado como medida de gratificações para as organizações que se sobressaem em suas obrigações (SOUZA; ROCHA, 2008). Os mecanismos capacitores são instrumentos que fomentam a capacidade dos membros da cadeia com o objetivo de sanar possíveis dificuldades na condução da GCl. Conforme Cooper e Slagmulder (1999), o propósito desses mecanismos é colaborar com as empresas da cadeia, no intuito de atingirem suas metas de redução de custos, conciliando as habilidades e os esforços dos envolvidos no processo.

Os mecanismos incentivadores, por sua vez, regulam a distribuição dos benefícios gerados pela GCl. Na visão de Souza e Rocha (2009), esses mecanismos podem ser considerados como instrumentos gerenciais que servem de suporte à GCl. Segundo os autores, uma contabilidade gerencial que produz dados não confiáveis passa a ser um obstáculo à prática da $\mathrm{GCl}$, já que informações confiáveis são fundamentais para o desenvolvimento da confiança entre os membros da cadeia. Outra variável que deve ser observada é o comprometimento com a redução de custos no longo prazo (KAJUTER; KULMALA, 2005), e para tanto, é necessário que haja compartilhamento de informações e controle dos custos da cadeia de suprimentos.

\subsection{Relacionamento comprador-fornecedor na cadeia de suprimentos e OBA}

O relacionamento comprador-fornecedor tem sido foco de estudos na área de negócios nas últimas décadas, a nível nacional e internacional (COOPER; SLAGMULDER, 1999; KAJÜTER; KULMALA, 2005; WEI; XU; HU, 2013; FEHR; ROCHA, 2018). A principal razão é tentar entender a dinâmica desses relacionamentos, já que estes podem oferecer oportunidades para que as empresas numa cadeia de suprimentos consigam coordenar suas atividades e relacionar-se de maneira estratégica, buscando melhorias nos seus produtos, serviços, processos, e possibilidades de otimização de custos (COOPER; SLAGMULDER, 1999; KAJÜTER; KULMALA, 2005).

O relacionamento comprador-fornecedor se baseia em uma ligação díade, que pode ser orientada para a cooperação ou para uma transação via mercado. As relações transacionais geralmente são discretas, classificadas por tarefas ou funções que não são críticas para a organização, exibem baixos níveis de interdependência entre as partes, baixa especificidade de ativos, baixo grau de comprometimento, foco em benefícios próprios etc. (NYAGA; WHIPPLE; LYNCH, 2010).

Por sua vez, as relações de colaboração são contínuas, cooperativas e de longo prazo, com nível mais alto de interdependência e de comprometimento, e foco em benefícios mútuos. A ideia de que uma empresa não pode competir com sucesso de maneira isolada é a premissa central na condução das relações de colaboração (NYAGA; WHIPPLE; LYNCH, 2010).

Estudos anteriores sugerem que os relacionamentos colaborativos, de longo prazo, fornecem maiores vantagens que os relacionamentos transacionais, incluindo custos transacionais reduzidos e menor oportunismo do parceiro (AGNDAL; NILSSON, 2010; VILLENA; REVILLA; CHOI, 2011). Podem, ainda, permitir melhorias de qualidade, fornecer uma base de clientes confiável para o fornecedor e possibilitar a otimização dos custos (AGNDAL; NILSSON, 2010; WAGNER; BODE, 2014).

Essas questões que envolvem o universo dos relacionamentos interfirmas demonstram que a introdução e o aperfeiçoamento de práticas interorganizacionais, como a $\mathrm{GCl}$ e o OBA, permitem o estabelecimento de relações de cooperação e ampliação das fronteiras, passando a formar cadeias, conglomerados, redes e alianças com o propósito de reduzir os custos de transação e aumentar o volume de negócios (FEHR; ROCHA, 2018).

Considerando as relações interfirmas ocorridas em determinada cadeia de valor, o OBA se destaca por permitir a integração das empresas e facilitar a troca de informações relevantes entre entidades que compõem uma cadeia (KAJÜTER; KULMALA, 2005). Fehr e Rocha (2018) definem o OBA como um processo 
de compartilhamento de informações entre empresas, inicialmente confidenciais, relacionadas a custos, processos e/ou atividades, entre as partes em um relacionamento, com o objetivo de otimizar a gestão de custos, definição esta utilizada neste trabalho. Optou-se pela utilização do termo em inglês Open-Book Accounting (OBA) por não haver ainda uma tradução consolidada na literatura.

A prática do OBA exige que as partes interessadas divulguem suas próprias informações de custo com um certo mecanismo formal, incluindo custos de uma peça, nível salarial e até lucro marginal, além de outras informações relevantes (KAJÜTER; KULMALA, 2005). Kulmala (2004) observa que o processo de compartilhamento de informações contábeis leva uma empresa a mostrar os seus custos às outras, bem como trocar soluções conjuntas para otimiza-los, além de melhorar o seu posicionamento entre os concorrentes. Nessa relação, clientes conseguem usar as informações de custos para ajustar preços e fornecedores também conseguem praticar preços mais competitivos (KAJÜTER; KULMALA, 2005). Para Cooper e Slagmulder (1999), esse compartilhamento de informações só seria possível em um ambiente de interdependência, cooperação e confiança.

No entanto, diversos fatores podem influenciar a implementação do OBA, pois em alguns casos as empresas não têm interesse em divulgar suas informações, principalmente se forem relativas a custos (KAJÜTER; KULMALA, 2005). Assim, para os autores, somente em circunstâncias particulares o OBA teria sucesso e as agrupam em três fatores: exógenos à firma, específicos da firma e específicos da cadeia de valor. Fatores ambientais exógenos à firma referem-se, por exemplo, à competição intensiva, causando uma pressão contínua de redução de custos, o que propicia a utilização de enfoques colaborativos de $\mathrm{GCl}$ e de OBA.

Como parte dos fatores específicos da cadeia de valor desponta-se a confiança, pois influencia os agentes a considerarem que é improvável o uso indevido das informações divulgadas. Nesse caso, o OBA fornece dois tipos de ajuda: garante confiança e favorece a ocorrência de eventos de colaboração (KAJUTER; KULMALA, 2005). A necessidade de garantias e de confiança normalmente está ligada ao gerenciamento das preocupações quanto ao custo econômico das transações, no sentido de se proteger ou não contra o potencial oportunismo. Já a informação que permite mais eventos de colaboração resulta na possibilidade de as entidades planejarem o futuro e tomarem decisões de forma conjunta e colaborativa.

Quanto aos fatores específicos das firmas, por um lado a deficiência e diversidade nos sistemas de contabilidade de custos são barreiras para a utilização do OBA. Empresas, por vezes, não abrem sua contabilidade por acreditarem que as informações geradas não são acuradas. Ademais, os sistemas de informações podem ser bastante específicos, dificultando o compartilhamento de informações. Por outro lado, dados dos sistemas de contabilidade de custos entendidos como seguros podem contribuir para a utilização do OBA.

Os fatores apresentados influenciam o processo de compartilhamento de informações em uma cadeia de valor. Assim, um conjunto de requisitos precisa ser cumprido para assegurar o alcance das expectativas em relação ao OBA (KAJUTER; KULMALA, 2005). No entanto, ainda há poucas indicações, segundo Kumra, Agndal e Nilsson (2012), de que as empresas estejam adotando políticas de OBA para aumentar a eficiência da cadeia de suprimentos, o que denota a importância de estudos empíricos para verificar como as informações de custos estão sendo divulgadas entre os negociantes.

Na sequência, aborda-se a Economia de Custos de Transação (ECT), teria de base do estudo, visto que fatores preconizados por ela influenciam a aplicação do OBA, a exemplo do oportunismo das partes, o investimento em ativos específicos, a necessidade de salvaguardas, a frequência das transações, dentre outros.

\subsection{Economia de Custos de Transação (ECT)}

Partindo das análises de Coase $(1937,1988)$ sobre a natureza da firma e dos custos de transação e seus desdobramentos, Williamson $(1993,1996)$ sistematizou a Teoria dos Custos de Transação ou Economia dos Custos de Transação (ECT), conforme mostrado na Figura 2, a seguir, a fim de consolidar a ideia de que a estrutura institucional do sistema econômico impacta significativamente o funcionamento do mercado e, por consequência, da firma.

Com base nas características das transações (especificidade dos ativos, frequência, risco/incerteza, etc.) e nos pressupostos comportamentais de racionalidade limitada e oportunismo, Williamson $(1993,1996)$ apresenta seu constructo teórico que busca explicar o alinhamento entre as características das transações e as formas de governança, sob a égide do comportamento eficiente de minimização dos custos de produção e de transação. 
Figura 2 - Estrutura Conceitual da ECT

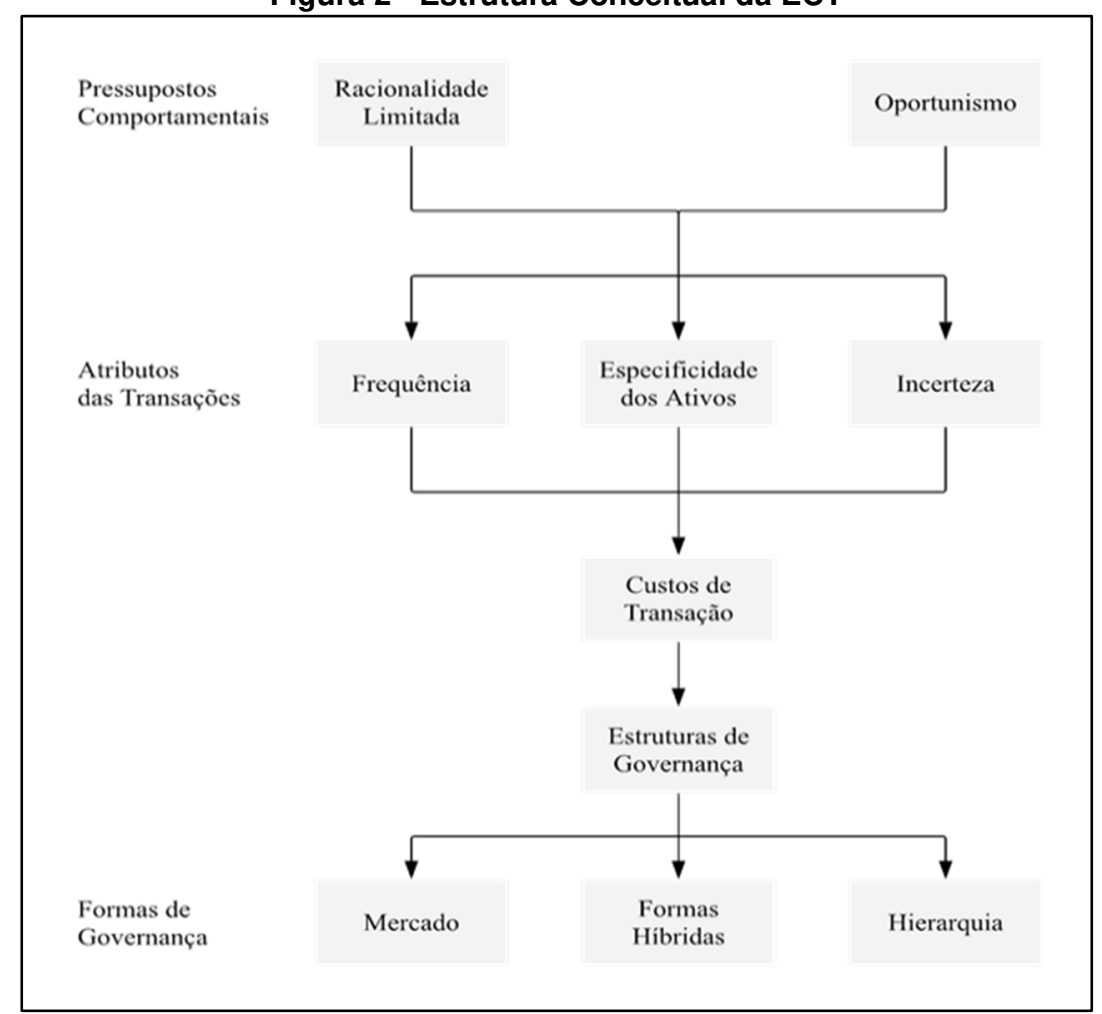

Fonte: Desenvolvido a partir de Williamson $(1993,1996)$ e Guedes $(2000)$

Williamson $(1993,1996)$ apresenta a ECT em quatro vértices fundamentais: custos de transação, ambiente institucional, racionalidade limitada e oportunismo, conforme apresentado no Quadro 2.

\section{Quadro 2 - Vértices Fundamentais da ECT}

\begin{tabular}{|c|l|}
\hline Vértices & \multicolumn{1}{|c|}{ Descrição/Características } \\
\hline $\begin{array}{c}\text { Custos de } \\
\text { transação }\end{array}$ & $\begin{array}{l}\text { Aparecem tanto na utilização do sistema de preços como em transações regidas por contratos } \\
\text { internos à firma, o que significa que todos os tipos de contratos (externos ou internos à firma) são } \\
\text { importantes para o funcionamento da economia. }\end{array}$ \\
\hline $\begin{array}{c}\text { Ambiente } \\
\text { institucional }\end{array}$ & $\begin{array}{l}\text { As transações ocorrem em ambientes institucionais estruturados (regulamentos formais ou } \\
\text { informais nos diversos agrupamentos sociais) e as instituições interferem nos custos de } \\
\text { transação, por afetarem o processo de transferência dos direitos de propriedade (uso, controle e } \\
\text { apropriação de resultados dos ativos). }\end{array}$ \\
\hline $\begin{array}{c}\text { Racionalidade } \\
\text { limitada }\end{array}$ & $\begin{array}{l}\text { Considera-se que o agente econômico busca um comportamento otimizador e racional, mas não } \\
\text { consegue satisfazer esse desejo dado sua limitação na capacidade cognitiva de receber, } \\
\text { armazenar, recuperar e processar informações, o que faz com que não seja totalmente racional } \\
\text { em suas decisões. }\end{array}$ \\
\hline Oportunismo & $\begin{array}{l}\text { Conceito que resulta da ação dos indivíduos na busca de seu autointeresse, mas com uma } \\
\text { conotação não cooperativa. Pode ocorrer, por exemplo, quando um agente tem uma informação } \\
\text { sobre a realidade não disponível a outro agente, e ela é utilizada de modo a permitir que o primeiro } \\
\text { desfrute de algum benefício do tipo monopolístico. }\end{array}$ \\
\hline
\end{tabular}

Fonte: desenvolvido a partir de Williamson (1993, 1996) e Zylbersztajn (1995).

Portanto, apresentados os vértices, percebe-se que a ECT tem como objeto principal de análise as transações entre os agentes econômicos, em determinado ambiente institucional (externo e interno às firmas). Busca explicar e, se possível, prever a dinâmica dessas transações, com base na premissa de que os agentes têm como objetivo final minimizar os custos de transação em busca de maior eficiência econômica (COASE, 1988; WILLIAMSON, 1993; ZYLBERSZTAJN, 1995).

\section{Procedimentos Metodológicos}

Em relação ao problema, esta pesquisa se caracteriza como qualitativa. Segundo Denzin (2018), na pesquisa qualitativa o enfoque principal são as pessoas e suas relações com os outros, considerando o meio social em que vivem e atuam tanto pessoal quanto profissional. Quanto aos objetivos, trata-se de um estudo descritivo, pois busca-se a descrição de como o OBA é praticado no relacionamento analisado. Já quanto aos procedimentos técnicos, refere-se a um estudo de caso, em que se "investiga um fenômeno contemporâneo 
dentro do seu contexto da vida real, especificamente quando os limites entre o fenômeno e o contexto não estão claramente definidos" (YIN, 2010, p. 32).

O estudo de caso utiliza diversas técnicas de coleta de dados como: entrevista, observação e análise de documentos (CRESWELL, 2014; MARTINS, 2008). Essas técnicas são confrontadas por meio de uma triangulação no sentido de se obter informações mais detalhadas e confiáveis que gerem resultados também confiáveis e de qualidade (GIBBS; COSTA, 2009). A triangulação, nesse sentido, busca contrapor a informação obtida por uma fonte com outras, visando corroborar os resultados da pesquisa (GIL, 2010). As técnicas de coleta de dados empregadas neste estudo de caso foram entrevistas semiestruturadas, análise documental, observação direta não participante e análise cruzada das informações das entrevistas, conforme explicitadas na sequência.

Dado o objetivo da pesquisa, escolheu-se empresas que apresentassem relacionamentos colaborativos, de longo prazo, e não relações meramente transacionais. Com isso, a seleção das empresas e dos entrevistados ocorreu por meio de amostragem intencional ou por julgamento. Foram pesquisados uma compradora agroindustrial e um dos seus fornecedores diretos, sendo, portanto, uma pesquisa que aborda uma díade. Com o intuito de se manter a confidencialidade, os nomes das empresas foram omitidos, assim como dos entrevistados, sendo adotados os seguintes codinomes para as empresas: Compradora e Fornecedor. Para os entrevistados, adotou-se Entrevistado X1 e Entrevistado X2, relativos à Compradora, e Entrevistado $\mathrm{Y}$, do Fornecedor. Algumas informações sobre as empresas também foram desconsideradas para que as mesmas não fossem identificadas.

\subsection{Coleta dos dados}

Para a coleta de dados utilizaram-se quatro fontes: entrevista semiestruturada, análise documental, observação direta não participante e análise cruzada das informações das entrevistas. Essas técnicas foram confrontadas por meio da triangulação.

Para realização das entrevistas semiestruturadas, utilizou-se o roteiro de entrevista, adaptado de Fehr e Rocha (2018), o qual passou por um pré-teste com um gestor de compras de uma outra multinacional do agronegócio para verificar a necessidade de ajustes. Essa entrevista teve duração aproximada de 180 minutos e teve o propósito de verificar o entendimento em relação às perguntas e eliminar as ambiguidades e ambivalências. Assim, em alguns pontos do roteiro foram realizados ajustes (substituição de palavras, reescrita de perguntas, diminuição de termos técnicos) após serem discutidos e julgados pertinentes.

As entrevistas realizadas ocorreram no período compreendido entre junho de 2018 a janeiro de 2019. Os respondentes foram gestores ligados ao Departamento de Compras na empresa compradora e ao Departamento de Vendas no fornecedor, por serem as pessoas que fazem o contato entre empresas estudadas e possuírem conhecimento aprofundado sobre o relacionamento e o compartilhamento de informações de custos, processos e/ou atividades.

Por meio da pesquisa documental, obtiveram-se informações para melhor entendimento do relacionamento analisado e do processo de compartilhamento de informações. Analisou-se um documento denominado Template, que compõe um conjunto de documentos internos utilizados pela empresa compradora. O Template foi fornecido pela Compradora, contendo estudo de mercado do negócio contratado com o Fornecedor, tabela com os principais custos e insumos do fornecedor, além de dados tratados (inclusive de agências especializadas) sobre concorrentes, fornecedores, análise do mercado de suprimentos, análise da cadeia de valor dessas duas empresas e de concorrentes. Analisaram-se, também, o contrato formal, regulamentos e protocolos do relacionamento (minutas e aditivo de contrato), e informações disponíveis nos sites das empresas e revistas especializadas do setor. O Quadro 3, na sequência, exibe as informações sobre os entrevistados, a duração das entrevistas, da observação e da análise documental.

Quadro 1 - Dados das entrevistas, análise documental e observação.

\begin{tabular}{|c|c|c|c|c|c|c|c|c|}
\hline \multirow{3}{*}{ Empresas } & \multirow{3}{*}{ Entrevistado } & \multirow{3}{*}{ Cargo } & \multirow{3}{*}{$\begin{array}{c}\text { Tempo } \\
\text { no } \\
\text { cargo }\end{array}$} & \multirow{3}{*}{$\begin{array}{c}\text { Tempo } \\
\text { no } \\
\text { setor }\end{array}$} & \multirow{2}{*}{\multicolumn{2}{|c|}{ Entrevistas }} & \multirow{3}{*}{$\begin{array}{c}\begin{array}{c}\text { Obser } \\
\text { vação }\end{array} \\
D^{\star}\end{array}$} & \multirow{3}{*}{$\begin{array}{c}\begin{array}{c}\text { Análise de } \\
\text { Documentos }\end{array} \\
\text { Tipos }\end{array}$} \\
\hline & & & & & & & & \\
\hline & & & & & $D^{*}$ & $Q^{\star \star}$ & & \\
\hline \multirow{2}{*}{ Compradora } & $\begin{array}{c}\text { Entrevistado } \\
\text { X1 }\end{array}$ & $\begin{array}{c}\text { Gerente de } \\
\text { Compras }\end{array}$ & 3 anos & $\begin{array}{c}10 \\
\text { anos }\end{array}$ & 223 & 28 & \multirow{3}{*}{90} & \multirow{4}{*}{$\begin{array}{c}\text { Template, } \\
\text { Contrato, } \\
\text { Minutas do } \\
\text { contrato, } \\
\text { Relatórios } \\
\text { disponíveis nos } \\
\text { sites das } \\
\text { empresas, } \\
\text { Boletins do } \\
\text { mercado/setor. }\end{array}$} \\
\hline & $\begin{array}{c}\text { Entrevistado } \\
\mathrm{X} 2 \\
\end{array}$ & $\begin{array}{c}\text { Comprador } \\
\text { Sênior }\end{array}$ & 3 anos & 3 anos & 97 & 18 & & \\
\hline Fornecedor & Entrevistado $\mathrm{Y}$ & $\begin{array}{l}\text { Executivo } \\
\text { de Contas }\end{array}$ & 7 anos & 7 anos & 74 & 16 & & \\
\hline \multicolumn{5}{|c|}{$\begin{array}{l}\text { Tempo total das entrevistas (somadas as entrevistas } \\
\text { originais e complementares) e da observação }\end{array}$} & 394 & 62 & 90 & \\
\hline
\end{tabular}

* Duração em minutos; ** Quantidade de páginas transcritas

Fonte: Elaborado pelo autor. 
Quanto à observação direta, como o Fornecedor desenvolve parte das atividades contratadas nas dependências da Compradora, foram observados protocolos de suporte e soluções de problemas por meio de visita orientada ao chão de fábrica da compradora, especificamente, o processo de produção em que 0 Fornecedor tem participação. O engenheiro que atua na função de gerente da fábrica na empresa compradora, embora não tenha sido entrevistado, foi quem demonstrou o processo de produção. Ele explicou sobre a integração do serviço do Fornecedor no processo produtivo da Compradora e sobre questões referentes ao relacionamento entre as empresas.

As entrevistas foram gravadas e transcritas, e, com a transcrição, verificou-se a necessidade de complemento de algumas informações, sendo realizadas entrevistas complementares com todos os entrevistados.

\subsection{Tratamento dos Dados}

Para análise dos dados empregou-se a Análise de Conteúdo (AC). Segundo Bardin (2011), a AC é um conjunto de instrumentos metodológicos que busca compreender, analisar, sintetizar e descrever, cientificamente e com rigor, as imagens, as palavras, os textos escritos, os discursos pronunciados, além de outros conteúdos temáticos. Embora a AC apresente também a abordagem quantitativa, que tem por base a frequência de aparição de determinados elementos da mensagem, nesta pesquisa optou-se pela abordagem qualitativa, por esta permitir inferir certas características particulares presentes nos discursos dos informantes que vão além da frequência de aparição de certos elementos no discurso analisado (BARDIN, 2011).

A análise qualitativa é válida na elaboração de deduções específicas sobre um acontecimento ou uma variável precisa, formando um índice (tema, palavra, unidade de contexto etc.), não se restringindo à frequência com que aparece, mas sobretudo na presença ou na ausência da variável em análise, presente na comunicação ou discurso (BARDIN, 2011). Os dados secundários e as entrevistas foram interpretados por esse método de análise e os achados foram classificados em categorias de análise baseadas no referencial teórico, conforme exibe o Quadro 4, da seção 3.3.

\subsection{Operacionalização das categorias de análise}

O Quadro 4 traz a categorização de análise desenvolvida para este estudo acerca do OBA, da GCI e da ECT, presentes no contexto dos relacionamentos interorganizacionais.

Quadro 2 - Categorização e detalhamento das variáveis investigadas

\begin{tabular}{|c|c|c|}
\hline & Categorias & Detalhamento ou subcategories \\
\hline 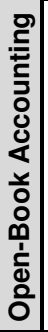 & Dimensões do OBA & $\begin{array}{l}\text { - Natureza das informações; - Tipo da informação; } \\
\text { - Frequência do compartilhamento das informações; } \\
\text { - Nível de detalhe das informações; } \\
\text { - Direção do compartilhamento das informações; } \\
\text { - Propósitos de uso das informações na perspectiva do comprador; } \\
\text { - Propósitos de uso das informações na perspectiva do fornecedor; } \\
\text { - Processos que contempla; - Forma de comunicação; } \\
\text { - Determinantes de custos que contempla; } \\
\text { - Condições do compartilhamento de informações; } \\
\text { - Incentivos para o compartilhamento de informações. }\end{array}$ \\
\hline $\bar{\circlearrowleft}$ & $\begin{array}{l}\text { Gestão de custos interorganizacionais } \\
\text { Desenvolvimento de atividades conjuntas }\end{array}$ & $\begin{array}{l}\text { - Times interorganizacionais; } \\
\text { - Processos conjuntos para gestão de custos; } \\
\text { - Planejamento conjunto para resolução de problemas. }\end{array}$ \\
\hline \multirow{5}{*}{ 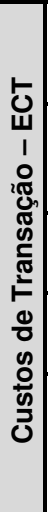 } & $\begin{array}{c}\text { Especificidade de ativos } \\
\text { Grau de redistribuição de um ativo para uso } \\
\text { alternativo }\end{array}$ & $\begin{array}{l}\text { - Investimentos em ativos específicos; } \\
\text { - Realocação/redistribuição dos ativos; } \\
\text { - Perdas de valor nos investimentos sob ruptura de contrato. }\end{array}$ \\
\hline & $\begin{array}{l}\text { Salvaguardas } \\
\text { Regras e normas formais e /informais }\end{array}$ & $\begin{array}{l}\text { - Salvaguardas formais; - Salvaguardas informais; } \\
\text { - Flexibilidade em dar suporte um ao outro; } \\
\text { - Estabelecimento de benefícios mútuos. }\end{array}$ \\
\hline & $\begin{array}{l}\text { Comportamento Oportunista } \\
\text { Autointeresse (com avidez) }\end{array}$ & $\begin{array}{l}\text { - Uso indevido das informações compartilhadas; } \\
\text { - Violação de acordos (formais e informais) em benefício próprio. }\end{array}$ \\
\hline & $\begin{array}{c}\text { Frequência } \\
\text { Quantidade de transações realizadas }\end{array}$ & $\begin{array}{l}\text { - Frequência de compartilhamento de informações; } \\
\text { - Frequência de entrega de produtos/componentes. }\end{array}$ \\
\hline & $\begin{array}{c}\text { Incerteza } \\
\text { Mudanças não antecipadas e imprevisíveis } \\
\text { nas circunstâncias } \\
\text { em que a relação está inserida }\end{array}$ & $\begin{array}{l}\text { - Ações tomadas quando da mudança nos planos e programas de produção; } \\
\text { - Comunicação a quem e com que antecedência quanto a essas mudanças. }\end{array}$ \\
\hline
\end{tabular}

Foi realizada a categorização dos trechos das entrevistas com base nas categorias propostas no Quadro 4, tendo a ECT como suporte. 


\section{Análise, Interpretação e Discussão dos Resultados}

\subsection{Descrição das empresas e características do relacionamento}

A Compradora é uma processadora de oleaginosa atuante no mercado global, de matriz americana. Compõem suas atividades a comercialização e processamento de grãos, fabricação de óleos vegetais e outros ingredientes e insumos para a indústria alimentícia e de nutrição animal e a produção de biodiesel. É uma empresa verticalmente integrada com operações de sourcing, produção e transporte (logística) de produtos agrícolas.

Já o Fornecedor, de matriz também americana, atua em três divisões no Brasil: florestal, papel kraft e papelão ondulado (embalagem). Sua estrutura é verticalizada, integrada desde a originação das fibras de celulose, passando pela produção de papel e conversão de papelão ondulado a partir do papel kraft. A empresa oferta projeto estrutural e gráfico, e serviços de engenharia e máquinas de embalagem automatizadas, com soluções de instalação, automação e integração de linha e embalagem.

O relacionamento entre a Compradora e o Fornecedor ocorre na categoria de insumos de fábrica, especificamente embalagens (packaging), que é a área responsável por soluções em embalagens e paletização, considerada estratégica pela Compradora. Trata-se de um contrato de fornecimento de caixas de papelão kraft atrelado a empréstimo de máquinas encaixotadoras (ativo específico), instaladas na linha de produção da Compradora, em mais de uma unidade fabril. A caixa de papelão kraft possui uma tecnologia própria patenteada pelo Fornecedor, que aumenta a sua resistência e performance na linha de produção. As máquinas encaixotadoras são feitas sob medida para atender às necessidades da Compradora. Segundo o gestor de compras da Compradora, a dependência com o Fornecedor na operação é alta e por isso envolve risco.

Esse relacionamento foi construído ao longo de seis anos, com início em 2012. A princípio, era um fornecedor para compra transacional, sem contrato formalizado, e, no decorrer do tempo, tornou-se estratégico. Devido ao relacionamento construído, a Compradora firmou um novo contrato de mais oito anos de exclusividade com o Fornecedor. A estratégia da Compradora de reduzir os custos de embalagens na cadeia se justifica por ela ser uma grande produtora de óleo, tendo um volume de compras de cerca de dois milhões de caixas de embalagem de óleo, por mês, desse fornecedor.

Para controlar suas atividades com o Fornecedor, a Compradora faz uso de um programa de gerenciamento e classificação de fornecedor, e gere os serviços em suas operações, devido ao envolvimento do Fornecedor com o seu modelo de produção, que é considerado crítico e com entregas diárias, de forma direta e sequenciada.

A receita bruta do Fornecedor proveniente das vendas para a Compradora gira em torno de $3 \%$ a $5 \%$ da receita bruta total da empresa no Brasil, o que indica que o mesmo não é seu dependente economicamente. O Fornecedor possui em sua carteira outros grandes clientes no Brasil, mas a Compradora está entre os sete maiores, sendo que o maior representa entre $10 \%$ a $15 \%$ do faturamento da empresa.

Devido à exclusividade e a perspectividade de ampliação de negócios, o Fornecedor precisa ser antecipadamente informado sobre planos de aquisição e expansão da produção da Compradora para que consiga planejar e programar sua produção e para que não corra o risco de faltar o componente fornecido na linha de produção da Compradora, já que ambas as empresas trabalham com estoque mínimo de materiais.

\subsection{Análise e discussão do caso}

A Compradora utiliza a estratégia de terceirização por entender que esta atende às suas necessidades, e que o contrato com terceiros é realizado apenas se a opção de produzir internamente determinado bem ou serviço não for mais vantajosa para a empresa. Para tomar decisões no contexto do seu negócio, a Compradora utiliza as informações geradas com a utilização do TCO (Total Cost of Ownership), tornando possível sua estratégia de liderança em custos (PORTER, 1991). Esse posicionamento da empresa corrobora a literatura sobre GEC, que preconiza que uma vantagem competitiva é alcançada quando há gestão de custos focada na gestão estratégica do negócio (SHANK; GOVINDARAJAN, 1997; HANSEN; MOWEN, 2010; SOUZA; HEINEN, 2012).

Para aplicar o TCO, a Compradora desenvolve um estudo ampliado de mercado para construção daquilo que ela mesma denominou de Template, que contém dados tratados (inclusive por agências especializadas que cobram pela disponibilização das informações) sobre concorrentes, fornecedores, análise do mercado de suprimentos, análise da cadeia de valor de determinado segmento, e outros dados da cadeia de valor em que está inserida. O objetivo é a construção da sua strategic sourcing (estratégia de fornecimento ou abastecimento) com o propósito final de "economizar dinheiro", conforme a fala do Entrevistado X1, melhorando o processo de aquisição, o desempenho do fornecedor e minimizando os riscos.

(...) então usando a ferramenta de strategic sourcing, eu [Compradora] olhei pra dentro da cadeia de valor e vi o que eu podia fazer pra reduzir meu custo total, e fui fazer uma análise de TCO dentro da minha cadeia. Porque eu recebo tampa, rótulo e pet [garrafa] dentro de caixa dos meus [outros] 
fornecedores também. Então eu fui lá no Fornecedor e falei: eu preciso reduzir porque você concorda que caixa é um elemento do custo do meu fornecedor de tampa, pet e rótulo? Então você vai negociar com esses caras pra reduzir os custos deles porque eles vão repassar [essa redução nos custos] pra mim. Foi por isso então que eu sugeri que o Fornecedor fosse nesses meus fornecedores negociar as caixas com eles também (...) os meus fornecedores de pré-forma [garrafa] não tinham o Fornecedor como fornecedor deles. Eles compravam caixas de outro fornecedor. Então por minha causa, o Fornecedor ganhou um novo cliente. (Entrevistado X1, comunicação pessoal, junho de 2018).

Hansen e Mowen (2010) sustentam que a construção de estratégias que envolvem a análise da cadeia de valor produz mudanças organizacionais que alteram a demanda por informações, especialmente de custos. No caso analisado, a aplicação do TCO pela Compradora demanda um intenso fluxo de informações sustentado pelo OBA. Embora, nesse relacionamento, o OBA seja também usado no contexto da $\mathrm{GCl}$, sua principal finalidade é apoiar o TCO. Este é um achado que não se encontrou referência na literatura pesquisada.

(...) eu só consigo ter essa abertura de informações, nesse nível, porque eu tenho um trabalho de aplicação de ferramenta de strategic sourcing [TCO] com ele ao longo do tempo que criou um relacionamento tamanho que hoje a gente vem pra mesa aberta [custos e outras informações de processos e atividades], eu e ele. (Entrevistado X1, comunicação pessoal, junho de 2018).

Com o intuito de se obter informações adicionais para subsidiar as análises, os sentidos das palavras presentes nos discursos dos entrevistados foram interpretados, por meio da nuvem de palavras e da análise de similitudes. Verificou-se que a palavra "informação" ocupa a posição mais destacada, sendo, portanto, o termo mais usado pelos entrevistados, confirmando a relevância da troca de informações no relacionamento analisado.

Em relação à direção do compartilhamento de informações, constatou-se que este ocorre bilateralmente, ou seja, tanto o Fornecedor quanto a Compradora compartilham suas informações, de forma díade, não havendo envolvimento de outras empresas da cadeia de suprimentos. Não há formalização para o compartilhamento de informações por parte da Compradora, mas existe no sentido contrário. Esse achado, compartilhamento bilateral, contraria parte da literatura sobre o OBA, a exemplo de Windolph e Moeller (2012) e Fehr e Rocha (2018), que mostraram que, geralmente, apenas o fornecedor compartilha suas informações. Porém, é importante destacar a existência de determinadas especificidades no relacionamento analisado, como a dependência da Compradora em relação ao Fornecedor, o que não se aplica a este último, considerando a diversificação de suas fontes de receitas.

Quanto ao nível de detalhes das informações compartilhadas, que está relacionado ao tipo e à natureza das informações e à sua agregação ou não (FEHR; ROCHA, 2018), foi possível verificar que no sentido do Fornecedor para a Compradora, o compartilhamento ocorre com um nível de detalhamento amplo, e no sentido contrário, o nível de detalhe é mais restrito. Isso pode ser explicado pelo fato de que em uma relação de compra e venda, o vendedor tende a abrir mais informações (KAJÜTER; KULMALA, 2005).

Ressalta-se, pelas evidências, que a confiança foi um pré-requisito para o compartilhamento de informações (KULMALA, 2002), e, ao mesmo tempo, favoreceu o aumento no nível de detalhamento das informações compartilhadas- que não era alto quando iniciou o processo de compartilhamento-, já que a confiança reduz as chances de oportunismo (KAJÜTER; KULMALA, 2005).

(...) com relação ao mercado total que a gente vê, eu atendo só clientes grandes, o meu negócio são os grandes clientes (...) e assim, é um tipo de informação que você compartilha com empresa a partir do momento que ambas as empresas têm um sincronismo, uma idoneidade, e confiança principalmente. Não é de praxe assim do mercado você abrir essas informações, já começar dessa forma. Eu acho até que na Compradora isso foi puxado pela pessoa do [nome do Entrevistado X1]. Pelo estilo dele, o jeito dele, ele abraçou essa causa e a gente viu com bons olhos e isso foi compartilhado, foi mais ou menos assim. (Entrevistado Y, comunicação pessoal, novembro de 2018).

Por meio dos documentos analisados e das entrevistas, verificou-se que o compartilhamento de informações pelo Fornecedor ocorre, principalmente, por componente do produto e estrutura de custos, contemplando informações sobre custos com madeiras e aparas, amido, soda, mão-de-obra, energia elétrica, gás, frete, dentre outros. O Fornecedor não abre sua margem de lucro para a Compradora, pois essa informação compõe os custos de conversão, mas abre os custos de vários componentes de fabricação da caixa de papelão kraft. Foi possível verificar que a abertura dos custos das principais matérias-primas que compõem a fabricação da caixa são apresentados em percentuais, por consumo de recursos e, às vezes, valores monetários, a exemplo do custo com energia elétrica. Essas informações contemplam, ainda, atividades, processos (produção em curso, comercialização e logística), aspectos sobre qualidade e relações com fornecedores na cadeia de valor, por exemplo.

Em análise do contrato estabelecido entre as partes, observou-se que a Compradora pode solicitar notas fiscais de entrada e saída ao Fornecedor, o que possibilita chegar a cálculos mais precisos sobre seus custos. De acordo com o Entrevistado X1, é possível chegar a valores absolutos, o que foi corroborado pela fala do Entrevistado Y. Assim, são compartilhadas informações tanto físico-operacionais quanto monetárias. 
(...) a gente tem hoje (...) desde o contrato anterior né [e reproduzimos] pra esse novo contrato, a gente tem a estrutura de custos deles aberta, inclusive consta no contrato. Como é que funciona? Pra produção do insumo caixa de papelão, a gente tem uma planilha que ele tem em linhas gerais ali os principais (...) drivers de custo dele, então tem lá, por exemplo, madeira que é um componente pra fabricação de papel, tem amido, tem mão-de-obra (...) e a gente tem os pesos [de] quanto que cada um desses itens participa dos custos dele né, frete, energia elétrica, combustível, (...) uma série de itens nessa planilha de custos (...) e o que eles compartilham conosco (...) é o quanto variou cada um desses custos né. Eu não sei quanto que ele paga efetivamente pra cada um desses itens. Alguns itens, mais representativos, como o preço do papel kraft, que é o papel virgem, e o papelão reciclado, que ele utiliza pra fazer o miolinho da caixa, isso de maneira até informal ele compartilha (...). (Entrevistado X2, comunicação pessoal, novembro de 2018).

Já a Compradora compartilha suas informações apenas quando existe necessidade para que o Fornecedor possa atender alguma demanda específica da mesma. As informações são sobre previsão de vendas, mantendo o Fornecedor informado nos casos de replanejamento do plano de produção, de marketing de vendas, de lançamentos de novos produtos, qualidade de materiais, produtos e componentes utilizados no processo de envase e embalamento da produção. Muitas informações foram compartilhadas com o Fornecedor com o propósito de que este tivesse acesso à linha de produção da Compradora para conseguir negociar a encaixotadora nas especificações técnicas exigidas, integrar a engenharia da caixa de papelão ao novo maquinário, e para obtenção de melhorias no processo de envase da Compradora, o que resultou em ganhos de escala e consequente redução de custos. Isso permitiu que o Fornecedor tivesse acesso tanto à estrutura de custos com embalagens, no momento do envase, como ao seu processo produtivo.

$\mathrm{Na}$ relação ainda de compra e venda, o vendedor sempre vai abrir mais pra mim. Agora, do ponto de vista, por exemplo, quando eu dou pra ele a minha operação e ele está lá dentro, ele vive a minha operação, então ele tem informação que muito fornecedor não tem. Simplesmente um cara pode me vender e nunca entrar dentro da fábrica. Esse [Fornecedor] não, ele tem acesso dentro da minha operação. (Entrevistado X1, comunicação pessoal, setembro de 2018).

Ainda, o fato de ambas as empresas serem de grande porte, não conferindo uma posição de poder de uma sobre a outra (assimetria de poder), o que reduz as assimetrias informacionais resultantes das relações de poder (PORTER, 1989), pode contribuir para a bilateralidade do compartilhamento. O tamanho da empresa é um aspecto considerado importante pelo Entrevistado $Y$ para que se possa estabelecer confiança e compartilhar informações, pois mencionou não compartilhar informações com empresas pequenas. Esse achado merece atenção, visto que é um fator pouco explorado pela literatura no sentido de se entender o que falta para as pequenas empresas conseguirem se inserir nesse processo.

(...) foi uma estrutura de custos consensuada exclusivamente com a Compradora. O que a gente tem com o resto do mercado é um pouco diferente, que é: com o resto do mercado a gente fala em custo total de papel, com a Compradora a gente fala em custos de madeira e apara, a gente não fala de papel propriamente dito. Apara é resto de papelão que aquele senhorzinho cata na rua, é aquela oscilação de preço que tem. Chove, choveu muito, pouco papelão no mercado reciclado pra comprar, preço sobe. Tá calor, não tá chovendo, preço desce. Então assim, a gente tem essa estrutura exclusiva com a Compradora hoje. Eu acho que se eu pegar todos os contratos da nossa companhia, só ela tem esse contrato que é madeira e apara. O resto do mercado: junta essa madeira e apara em uma única palavra: papel. (Entrevistado Y, comunicação pessoal, novembro de 2018).

Qualquer informação que eu preciso, que a gente enxerga algum possível ganho de redução de custos, eles [Compradora] passam na hora... a nossa planta é aberta pra eles, tanto que a deles é aberta pra nós. (Entrevistado Y, comunicação pessoal, novembro de 2018).

O compartilhamento de informações pela Compradora, mesmo com nível baixo de detalhamento, pode gerar confiança, aumentar a disposição do Fornecedor em abrir mais amplamente suas informações e aumentar a possibilidade de identificação de oportunidades de otimização de custos (AGNDAL; NILSSON, 2010; VILLENA; REVILLA; CHOI, 2011). Ademais, com menor assimetria de informações, reduz-se o risco de oportunismo (KAJÜTER; KULMALA, 2005; WINDOLPH; MOELLER, 2012), e, consequentemente, os custos de transação, especialmente os de monitoramento (WILLIAMSON, 1985), conforme preconiza a ECT. Um aspecto que também não se encontrou referência na literatura, é que o OBA pode ser uma fonte de economia de escala: ao abrir suas informações, a Compradora obteve melhorias em seu processo produtivo e gerou ganhos de escala para si.

Em termos de frequência, o compartilhamento de informações sobre processos e atividades ocorre quase diariamente, devido ao envolvimento do Fornecedor no processo produtivo da Compradora. Assim, a área técnica fornece informações rotineiramente, porém o compartilhamento de informações de custos pelo Fornecedor ocorre quando se inicia um novo projeto e, depois, são compartilhadas a cada seis meses como uma prévia para negociação de preço e, oficialmente, uma vez por ano. A forma de comunicação utilizada para o compartilhamento das informações é via e-mail, telefone e reuniões presenciais.

Quanto aos processos, as informações compartilhadas pelo Fornecedor contemplam principalmente a produção em curso, comercialização e logística, e eventualmente, pré-produção e alguns estágios do projeto do produto. Conforme o Entrevistado Y, para o estabelecimento do novo contrato, que envolveu a aquisição 
de ativos específicos e novo formato de caixa de papelão, compartilharam-se diversas informações técnicas das áreas de engenharia, que precisam de informações para ajuste, validação e acompanhamento do projeto. Verificou-se, também, que são compartilhadas informações sobre quase todos os determinantes de custos, à exceção da estrutura de capitais, mesmo que o fluxo de informações sobre alguns determinantes ocorra de maneira limitada.

Apesar de as informações compartilhadas pelo Fornecedor serem utilizadas pela Compradora para gerar confiança, demonstrar compromisso mútuo, assegurar margens, identificar ineficiências, eliminar desperdícios, desenvolver produtos ou serviços (soluções) e aplicação da técnica de Engenharia de Valor, seu principal uso é para selecionar, negociar e renegociar com fornecedores (no caso dos reajustes), e identificar os custos de produção do fornecedor, cujo intuito é encontrar oportunidades para redução de custos. A análise de similitudes mostrou que o termo "custo" vincula-se a preço e a mercado, evidenciando que o custo, nesse relacionamento, tem por previsão a negociação de preço e o mercado como parâmetro de comparação.

As condições em que ocorrem o compartilhamento de informações podem indicar que são baseadas em confiança, ainda que parcial, e em cooperação, mesmo o Entrevistado $Y$ admitindo que em uma relação de compra e venda, o fornecedor compartilha mais detalhes. Já em relação aos incentivos para o compartilhamento de informações, o Entrevistado $Y$ aponta que o principal motivo é ser fornecedor exclusivo da Compradora. Caso a Compradora venha adquirir e/ou expandir a produção, o Fornecedor tem preferência de fornecimento, gerando aumento no volume de negócios mútuos, e benefícios para ambos.

(...) tem também no nosso contrato: qualquer aquisição que a [Compradora] fizer nós temos a preferência de fornecimento. Então, se a [Compradora] adquirir uma empresa no Brasil [como ocorreu recentemente] que a gente não é fornecedor, nós temos a preferência de fornecimento. O que é essa preferência? Nós darmos um custo [valor] pra gente chegar num número que seja viável pra mim e pra [Compradora], [para] retirar aquele determinado fornecedor e colocar a gente no lugar. (Entrevistado Y, comunicação pessoal, novembro de 2018).

O Quadro 5 apresenta um resumo das dimensões do OBA presentes no processo de compartilhamento das informações no relacionamento analisado. Verificou-se, nas entrevistas, que em caso de ruptura de contato, o Fornecedor conseguiria realocar as máquinas, que são ativos específicos investidos pelo mesmo, mas demandaria certo tempo e algumas adaptações, incorrendo, portanto, em perdas. Já a Compradora teria dificuldade em encontrar outro fornecedor que conseguisse atender sua demanda tanto em relação às máquinas como ao fornecimento das caixas. Esse fornecedor é um dos principais players do mercado no ramo de embalagens. No âmbito da ECT, é observado que cresce a dependência bilateral das partes e o interesse em estabelecer contratos de maior duração quando há ativos específicos investidos. Nesse caso, celebrar contratos de longo prazo é uma das formas de governança recomendada quando a transação envolver investimentos específicos das partes, objetivando a minimização dos riscos envolvidos no relacionamento (WILLIAMSON, 1993; 1996).

O Entrevistado X1 comenta que a Compradora acaba por ficar bastante vulnerável na relação, já que a mesma está garantindo um contrato de exclusividade para o Fornecedor pelo período de oito anos, cujo volume de compra está estabelecido no contrato. $O$ investimento em ativos específicos feito pelo Fornecedor nas operações da Compradora representa apenas $2 \%$ do valor total do faturamento a ser obtido com 0 fornecimento de caixas de papelão kraft ao longo dos oito anos.

Como forma de mitigar os riscos, a Compradora estabeleceu três importantes salvaguardas no contrato, por meio de cláusulas de competitividade, de performance e de multas. A cláusula de competitividade visa garantir que a Compradora esteja pagando um "bom preço" pelo produto vendido pelo Fornecedor. O estabelecimento de salvaguardas é apontado pela ETC como uma maneira de mitigar riscos de oportunismo, especialmente em relacionamentos de longo prazo, que envolvem ativos específicos (WILLIAMSON, 1996; ZYLBERSZTAJN; SZTAJN, 2005). A adoção de cláusulas de competitividade e de performance podem ser entendidas como salvaguardas contratuais, uma vez que estabelece sanções caso os produtos/serviços não estejam em conformidade com critérios pré-estabelecidos em contrato, conforme prevê a ECT (WILLIAMSON, 1985, 1996).

Pela análise de similitudes e da nuvem de palavras, contrato aparece como uma das palavras mais evocadas nas falas dos entrevistados, o qual se refere ao contrato formal. Isso pode indicar a sua importância no relacionamento e reforçar o fato de ser a principal salvaguarda utilizada, o que foi constatado também pelas entrevistas e pela análise documental, corroborando Fehr e Rocha (2018), Wagner e Bode (2014) e Paswan, Hirunyawipada e lyer (2017). Observou-se, ainda, que o contrato possui vinte páginas de direitos e deveres e mais vinte de anexos, com minutas anti-corrupção e antitruste.

Uma cláusula importante observada é a de sigilo, Mutual-Non-Disclosure Agreement (MNDA) ou Acordo de Não-Divulgação Mútua, com proteções bilaterais, que cobrem informações confidenciais/sigilosas e visa resguardar ambas as empresas. Os achados mostram que há certo equilíbrio nas cláusulas, no sentido de não resguardar mais a Compradora que o Fornecedor. $O$ Entrevistado $Y$ considera que $o$ contrato salvaguarda as duas partes de forma igualitária e justa "porque foi minuciosamente discutido por cerca de cinco meses", entre eles. 
Quadro 3 - Resumo das dimensões do OBA presentes no caso analisado

\begin{tabular}{|c|c|c|}
\hline $\begin{array}{l}\text { Dimensões } \\
\text { do OBA }\end{array}$ & Fornecedor para Compradora & Compradora para Fornecedor \\
\hline $\begin{array}{l}\text { Natureza das } \\
\text { informações }\end{array}$ & Físico-operacional e monetária. & Físico-operacional e monetária. \\
\hline Tipo de informação & $\begin{array}{l}\text { Custos de materiais diretos, de matéria-prima, de } \\
\text { materiais auxiliares, de mão de obra direta, de } \\
\text { transporte/frete, impostos, informações sobre } \\
\text { qualidade, informações sobre produtividade e } \\
\text { eficiência de produção e informações sobre novos } \\
\text { projetos. }\end{array}$ & $\begin{array}{l}\text { Previsão de vendas, custos de embalagens, } \\
\text { informações sobre processos de produção, } \\
\text { informações sobre qualidade, informações sobre } \\
\text { produtividade e eficiência de produção, } \\
\text { informações sobre novos projetos. }\end{array}$ \\
\hline $\begin{array}{l}\text { Frequência do } \\
\text { compartilhamento }\end{array}$ & $\begin{array}{l}\text { No mínimo, uma vez ao ano para negociação de } \\
\text { preço. E semanalmente sobre processos e } \\
\text { atividades. }\end{array}$ & $\begin{array}{l}\text { Indeterminada } \\
\text { (ocorre de maneira eventual) }\end{array}$ \\
\hline Nível de detalhe & Mais detalhado & Menos detalhado \\
\hline $\begin{array}{l}\text { Direção do } \\
\text { compartilhamento }\end{array}$ & \multicolumn{2}{|c|}{$\begin{array}{l}\text { Bilateral, porém com fluxo de informações mais intenso em termos de nível de detalhe e frequência no } \\
\text { sentido do Fornecedor para a Compradora. }\end{array}$} \\
\hline $\begin{array}{l}\text { Propósitos de uso das } \\
\text { informações } \\
\text { (na perspectiva do } \\
\text { comprador e na } \\
\text { perspectiva do } \\
\text { fornecedor) }\end{array}$ & $\begin{array}{l}\text { Na perspectiva da Compradora: selecionar, } \\
\text { negociar, renegociar e avaliar fornecedor, } \\
\text { identificar oportunidades para redução de custos, } \\
\text { melhorar os processos produtivos, desenvolver } \\
\text { novos produtos/serviços, garantir confiança, } \\
\text { desenvolver conjuntamente produtos, identificar } \\
\text { ineficiências do fornecedor, identificar margens de } \\
\text { lucro, custos de produção e o processo de } \\
\text { produção do fornecedor, aplicar técnicas de } \\
\text { gestão de custos (Engenharia de Valor) e eliminar } \\
\text { desperdícios. }\end{array}$ & $\begin{array}{l}\mathrm{Na} \mathrm{perspectiva} \mathrm{do} \mathrm{Fornecedor:} \mathrm{identificar} \\
\text { oportunidades de redução de custos, facilitar o } \\
\text { desenvolvimento de produtos e serviços, permitir } \\
\text { a otimização de produtos e serviços e conhecer o } \\
\text { processo de produção da compradora e identificar } \\
\text { ineficiências. }\end{array}$ \\
\hline $\begin{array}{l}\text { Processos que } \\
\text { contempla }\end{array}$ & $\begin{array}{l}\text { Alguns estágios do projeto do produto, pré- } \\
\text { produção, produção em curso, comercialização e } \\
\text { logística. }\end{array}$ & Projeto do produto e produção em curso. \\
\hline Forma de comunicação & \multicolumn{2}{|c|}{$\begin{array}{c}\text { E-mail, telefone (chamada de voz e troca de mensagens via aplicativo de celular) } \\
\text { e reuniões presenciais. }\end{array}$} \\
\hline $\begin{array}{l}\text { Determinantes de } \\
\text { custos que contempla }\end{array}$ & $\begin{array}{l}\text { Modelo de gestão, escala de produção, escopo da } \\
\text { produção, nível tecnológico, uso da capacidade, } \\
\text { fatores institucionais, projeto do produto, } \\
\text { tempestividade, comprometimento, qualidade do } \\
\text { produto, diversidade, nível de experiência, } \\
\text { relações na cadeia de valor, localização, arranjo } \\
\text { físico do sistema produtivo. }\end{array}$ & Projeto do produto e qualidade do produto. \\
\hline $\begin{array}{l}\text { Condições do } \\
\text { compartilhamento }\end{array}$ & \multicolumn{2}{|c|}{ Baseado em confiança, mesmo que parcial, e cooperação. } \\
\hline $\begin{array}{l}\text { Incentivos para o } \\
\text { compartilhamento }\end{array}$ & $\begin{array}{l}\text { Suporte na negociação de preços com outras } \\
\text { firmas, indicação de clientes, aumento no volume } \\
\text { de negócios mútuos, resolução de problemas } \\
\text { conjuntos e exclusividade de fornecimento à } \\
\text { Compradora. }\end{array}$ & Aumento de eficiência. \\
\hline
\end{tabular}

Fonte: dados da pesquisa.

Nessas circunstâncias, se por um lado os entrevistados destacam a confiança mútua como uma das salvaguardas, por outro, verifica-se que a mesma é parcial, devido aos mecanismos formais de salvaguardas adotados, certamente pelo risco de oportunismo (WILLIAMSON, 1991, 1993; PASWAN; HIRUNYAWIPADA; IYER, 2017). Williamson (1996) corrobora ao defender que não existe confiança pura, e por isso as transações sempre terão algum tipo de salvaguarda.

Verificou-se, pelas análises, que há o compromisso entre ambas as empresas em estabelecerem e desenvolverem atividades conjuntas para otimização, gestão e redução de custos na cadeia de suprimentos, mantendo uma relação de "ganha-ganha" (SADEGHIA; JOKAR, 2014). No entanto, não existem times interorganizacionais nesse relacionamento. O que se constatou foi que a Compradora possui uma equipe formada por pessoas de várias áreas (compras, comercial, frete, operação) e regiões (Brasil, Estados Unidos, França) que são eleitas para o processo de negociação junto ao Fornecedor.

O Fornecedor também possui uma equipe, denominada de times multifuncionais, formada por pessoas da gestão de projetos, de pedidos e customer service, além do próprio Entrevistado Y, responsável por atender as demandas da Compradora. Os times de ambas as empresas se unem na negociação de novos projetos, momento em que as áreas de engenharia das duas empresas se comunicam para analisar a viabilidade técnica e operacional do projeto. Portanto, durante a fase do projeto do produto/serviço, há intensa troca de informações de custos, processos e atividades.

A principal atividade conjunta empreendida é a aplicação da técnica de Engenharia de Valor para redução de custos por meio de mudanças no projeto do produto, o que está em linha com a literatura sobre GCI (COOPER; YOSHIKAWA, 1994; COOPER; SLAGMULDER, 2004; SOUZA; ROCHA, 2008). Posteriormente, é a Compradora que despende esforços para verificar oportunidades de redução de custos por meio de sua equipe de sourcing. Quanto aos mecanismos da GCI, foi possível identificar o uso do 
mecanismo capacitor pela aplicação do OBA e da Engenharia de Valor, e do incentivador, posto que há previsão de benefícios mútuos no relacionamento (SADEGHIA; JOKAR, 2014; DI; WANG, 2017).

Contudo, as atividades conjuntas não ocorrem de forma sistemática e regular. Estas são pontuais (quando surgem novos projetos) e eventuais (quando surgem oportunidades de redução de custos). No entanto, Windolph e Moeller (2012) destacam que a prática do OBA não implica, necessariamente, a aplicação da GCl.

Em síntese, os achados da pesquisa evidenciam um nível amplo de detalhamento de informações do Fornecedor para a Compradora, que a princípio, parece atender ao que é desejado por esta última. As evidências mostram que não há dependência econômica por parte do Fornecedor e o produto fornecido nas especificações exigidas pela Compradora, parece não ser facilmente encontrado no mercado, o que dificulta a eventual troca de fornecedor. Assim, a priori, o Fornecedor teria o poder de não aceitar um nível alto de detalhamento das informações compartilhadas. Porém, outros fatores podem justificar essa situação, como o fato de o contrato ter um prazo superior ao normalmente praticado no mercado e ser de exclusividade, o compartilhamento de informações por parte da Compradora, ainda que pontual e eventual, a confiança e a parceria desenvolvidas e a relação de "ganha-ganha" estabelecida.

Percebe-se, pelos resultados, a frequência alta das transações e redução das incertezas, o que certamente reduz os riscos de oportunismo e os custos de transação, conforme previsto pela ECT. As partes se valem de salvaguardas para se protegerem, sendo a principal delas o contrato formal, existindo, também, salvaguardas relacionais, a exemplo da confiança, mesmo que parcial, e do comprometimento.

Embora não ocorra de maneira regular, existem atividades conjuntas entre as partes que caracterizam certo uso da GCl, a exemplo da Engenharia de Valor. Entretanto, o OBA tem a finalidade principal de alimentar a ferramenta TCO usada pela Compradora, e para a gestão dos custos das mesmas a partir das informações recebidas do Fornecedor.

\section{Considerações Finais}

O presente estudo teve por objetivo identificar como o OBA é praticado no relacionamento entre uma empresa agroindustrial e um de seus fornecedores diretos, na perspectiva da ECT. Verificou-se, por um lado, que o OBA pode servir a propósitos não diretamente relacionados ao gerenciamento de custos interorganizacionais, como a seleção, negociação e renegociação com fornecedores. Por outro lado, esse processo de compartilhamento de informações pode permitir ao comprador ajudar o fornecedor a desenvolver suas habilidades com mais eficiência. Um benefício adicional é que a empresa compradora pode obter um conhecimento significativo sobre o mercado de suprimentos, e isso ser utilizado com outros fornecedores.

O OBA também pode ser uma maneira de aliviar a tensão que ocorre nas negociações, particularmente no que diz respeito ao reajuste de preço, caso os benefícios gerados pela economia de custos sejam aproveitados para ambos os negociantes. Ainda, o compartilhamento de informações de custos, processos e/ou atividades também sinaliza a disposição do fornecedor e do comprador em construir um relacionamento de longo prazo. Nesse sentido, o OBA desempenhou papel importante na avaliação geral do relacionamento analisado, já que as partes enfatizaram que a troca de informações é uma forma de mostrar confiança, possibilitar a construção de projetos conjuntos e reforçar o compromisso com o longo prazo.

Quanto às implicações gerenciais, os achados mostraram que, possivelmente, o tipo de relacionamento (de longo prazo, com oportunidades de ampliação de negócios, previsão de benefícios mútuos, contrato de exclusividade e compartilhamento bilateral de informações) faz com que o OBA seja praticado a um nível amplo de detalhamento de informações por parte do Fornecedor. Essa situação ocorre ainda que o Fornecedor não apresente dependência econômica em relação à Compradora, e mesmo que a principal utilidade do OBA seja para negociação de preços, no intuito de identificar oportunidades de redução de custos, diferentemente do que traz parte da literatura (KAJUTER; KULMALA, 2005; FEHR; ROCHA, 2018), que mostra que esse processo, por vezes, é unilateral e imposto.

Percebe-se, portanto, que muitas vezes na prática, O OBA é utilizado de maneira limitada no relacionamento comprador-fornecedor, tendo seu potencial de uso reduzido devido, por exemplo, aos atributos das transações, às estruturas de governança e ao risco de oportunismo dos agentes. Com isso, conclui-se que o OBA necessita ser mais bem avaliado pelos gestores e ser percebido como uma prática que visa o desenvolvimento de parcerias de longo prazo, pautadas no princípio do "ganha-ganha", com redução da assimetria de poder entre os participantes, fortalecimento e integração da cadeia de suprimentos e geração de vantagem competitiva sustentável frente às cadeias concorrentes.

Constatou-se, também, que a confiança foi um pré-requisito para aplicação do OBA e que, ao mesmo tempo, o compartilhamento mais aberto de informações, com previsão de benefícios para ambas as empresas (reduzindo o risco de oportunismo) favoreceu o aumento de confiança no relacionamento. A implicação disso é que a disposição para o compartilhamento e o aumento do nível de detalhamento das informações depende do princípio de "ganha-ganha", conforme aponta a literatura. A conclusão é que o compartilhamento consensual de informações, pautado em benefícios mútuos, aumenta a disposição ao uso do OBA e, consequentemente, as chances de identificação de oportunidades de otimização de custos. 
Quanto às implicações para a academia, verificou-se que o OBA tem o propósito principal de apoiar o TCO, empregado para seleção, negociação e renegociação com fornecedores, e para a gestão de custos no âmbito da Compradora, a partir das informações recebidas do Fornecedor, e não, necessariamente, para a gestão de custos de ambas as empresas. Teoricamente, o propósito principal do OBA é dar suporte para a gestão dos custos interorganizacionais. Isso implica a necessidade de mais pesquisas sobre o assunto, de forma a entender as razões das diferenças do que se observa na prática e do que é previsto na teoria. Concluise, portanto, que há uma lacuna entre a literatura sobre OBA no aspecto apresentado e a sua prática nas empresas analisadas.

Considera-se que esta pesquisa contribui para a ampliação de conhecimento nas áreas de Administração e Contabilidade quando integra conhecimentos sobre Gestão Estratégica de Custos, relacionamentos interorganizacionais e Economia de Custos de Transação. Ademais, o referencial teórico levantado, as discussões apresentadas e as análises desenvolvidas na perspectiva díade, podem colaborar para o avanço do conhecimento sobre a prática do OBA nos relacionamentos entre compradores e fornecedores.

Buscou-se contribuir, também, para a compreensão do relacionamento entre as empresas pesquisadas. Os achados mostraram que o relacionamento foi construído ao longo de seis anos, em que, no início, as compras com o Fornecedor eram transacionais, sem contrato formalizado, e, posteriormente, esse fornecedor tornou-se estratégico. Os resultados evidenciaram, ainda, que não há dependência econômica do Fornecedor em relação à Compradora, e, mesmo assim, sujeita-se ao compartilhamento de informações a um nível amplo de detalhamento. Isso ocorre, certamente, devido a fatores como a exclusividade de fornecimento com contrato de oito anos (o que não é praxe no setor), ao compartilhamento bilateral de informações, à confiança desenvolvida, ainda que parcial, e à previsão de benefícios mútuos. Ademais, o Fornecedor investe em ativos específicos na Compradora e tem alto envolvimento com o seu modelo de produção, considerado crítico e com entregas diárias, de forma direta e sequenciada, do insumo fornecido.

Dadas as características dos estudos qualitativos, em especial os estudos de caso, as conclusões deste trabalho se restringem ao momento em que a pesquisa foi realizada e às peculiaridades do relacionamento analisado, em especial no que diz respeito aos achados sobre o contexto do relacionamento. Enquanto estudo de caso único, este trabalho favoreceu o caráter exploratório das particularidades do OBA, especialmente no setor da agroindústria, em que, na literatura pesquisada, não se encontrou outros trabalhos sobre o assunto, indicando também pontos a serem estudados em pesquisas futuras.

Quanto às recomendações para futuras pesquisas, sugere-se aplicar esta pesquisa, ainda na agroindústria, com uma compradora e alguns de seus fornecedores diretos que forneçam produtos diferentes para verificar se há diferenças na aplicação do OBA. Sugere-se, também, incluir outras variáveis na análise, como a origem do capital das empresas investigadas, para verificar se fatores culturais interferem na aplicação dessa ferramenta. Por fim, outros fatores como o tamanho das empresas e a relação de poder poderiam ser incluídos em pesquisas futuras sobre a aplicação do OBA.

\section{Referências}

AGNDAL, H.; NILSSON, U. Different open book accounting practices for different purchasing strategies. Management Accounting, v. 21, n. 3, p. 147-166, set. 2010. https://doi.org/10.1016/j.mar.2010.04.001

AGNDAL, H.; NILSSON, U. Interorganizational cost management in the exchange process. Management Accounting Research, v. 20, n. 2, p. 85-101, 2009. https://doi.org/10.1016/j.mar.2008.07.001

AGNDAL, H.; NILSSON, U. Supply chain decision-making supported by an open books policy. International Journal of Production Economics, v. 116, n. 1, p. 154-167, nov. 2008.

https://doi.org/10.1016/j.ijpe.2008.08.038

ANDRADE, L. C. M.; TEIXEIRA, A. J. C.; FORTUNATO, G.; NOSSA, V. Determinantes para a utilização de práticas de contabilidade gerencial estratégica: um estudo empírico. RAM - Revista de Administração Mackenzie, v. 14, n.1, p.98-125, jan./fev. 2013. Disponível em: http://editorarevistas.mackenzie.br/index.php/RAM/article/view/2889/3954. Acesso em: 15 abr. 2017.

ANSARI, S. et al. Target costing: the next frontier in strategic cost management. New York: McGraw-Hill, 1997.

BARDIN, L. Análise de Conteúdo. São Paulo: Edições 70, 2011.

BASTOS, E. K. X.; ARAÚJO, B. C. Variações na Renda Real não Captadas pelo PIB: efeito termos de troca e efeito preços relativos entre comerciáveis e não comerciáveis - Brasil, 1991-2016. Brasília: IPEA, 2017. 
CAGLIO, A. To Disclose or Not to Disclose? An Investigation of the Antecedents and Effects of Open Book Accounting. European Accounting Review, v. 27, n. 2, p. 263-287, 2018.

https://doi.org/10.1080/09638180.2017.1315313

CAGLIO, A.; DITILLO, A. Opening the black box of management accounting information exchanges in buyer-supplier relationships. Management Accounting Research, v. 23, n. 2, p. 61-78, jun. 2012. https://doi.org/10.1016/j.mar.2012.03.001

CAMACHO, R. R.; ROCHA, W.; MORAES, R. O.; MARQUES, K. C. M. Evidências de práticas da gestão de custos interorganizacionais na cadeia de valor de hospitais privados no Brasil. RC\&C - Revista

Contabilidade e Controladoria, Curitiba, v. 6, n. 2, p. 90-105, mai./ago. 2014.

http://dx.doi.org/10.5380/rcc.v6i2.35117

COASE, R. H. The Firm, the market, and the law. Chicago, IL: The University of Chicago Press, 1988.

COASE, R. H. The Nature of the Firm. Economica, v. 4, n. 16, p. 386-405, nov. 1937. Disponível em: <http://onlinelibrary.wiley.com/wol1/doi/10.1111/j.1468-0335.1937.tb00002.x/full>.

COOPER, R.; SLAGMULDER, R. Interorganizational cost management and relational context. Accounting, Organization and Society, v.29, n.1, p.1-26, jan. 2004. https://doi.org/10.1016/S0361-3682(03)00020-5

COOPER, R.; SLAGMULDER, R. Supply chain development for the lean enterprise: interorganizational cost management. Productivity Press: Portland, 1999. 512 p.

COOPER, R.; YOSHIKAWA, T. Interorganizational cost management systems: the case of the TokyoYokohama-Kamakura supplier chain. International Journal of Production Economics, v. 37, p. 51-62, 1994. https://doi.org/10.1016/0925-5273(94)90007-8

CRESWELL, J. W. Investigação Qualitativa e Projeto de Pesquisa: escolhendo entre cinco abordagens. 3. ed. Porto Alegre: Penso, 2014.

DAY, G. S; REIBSTEIN, D. J. A dinâmica da estratégia competitiva. Rio de Janeiro: Campus, 1999.

DENZIN, N. K. Investigação Qualitativa Crítica. Revista Sociedade, Contabilidade e Gestão, Rio de Janeiro, v. 13, n. 1, p. 105-119, jan./abr. 2018. http://dx.doi.org/10.21446/scg_ufrj.v13i1.14178

DI, W.; WANG, S. Empirical research on the impact of open-book accounting on organizational performance. Research on Modern Higher Education, Hong Kong, v.2, p.199-204, 2017.

http://dx.doi.org/10.24104/rmhe/2017.02.02010

DUARTE, S. L. Gestão de custos interorganizacionais em organizações cooperativas e investorowned firms-IOFs no setor de cafeicultura no Brasil. 2017. 302 f. Tese (Doutorado em Contabilidade e Controladoria) - Departamento de Contabilidade e Atuária, Faculdade de Economia, Administração e Contabilidade, Universidade de São Paulo, São Paulo, 2017. http://dx.doi.org/10.11606/T.12.2017.tde14062017-104903

ELLRAM, L. M; SIFERD, S. P. Total cost of ownership: a key concept in strategic cost management decisions. Journal of business logistics, [s.I.], v.19, n.1, p. 55-84, 1998. Disponível em:

https://www.scopus.com/record/display.uri?eid=2-s2.00002102239\&origin=inward\&txGid=6a0b88636c15a74c70ac2b067fdc2a09. Acesso em: 13 abr. 2017.

FEHR, L. C. F. A.; ROCHA, W. Open-book accounting and trust: influence on buyer-supplier relationship. RAUSP Management Journal, São Paulo, v. 53, n. 4, p. 597-621, out. 2018.

http://dx.doi.org/10.1108/rausp-06-2018-0034

GIBBS, G.; COSTA, R. C. Análise de dados qualitativos. Porto Alegre: Artmed, 2009.

GIL, A. C. Como elaborar projetos de pesquisa. 5. ed. São Paulo: Atlas, 2010.

GRAFTON, J.; MUNDY, J. Relational contracting and the myth of trust: control in a co-opetitive setting, Management Accounting Research, v. 36, p. 24-42, set. 2017. https://doi.org/10.1016/j.mar.2016.07.008 
GUEDES, S. N. R. Verticalização da agroindústria canavieira e a regulação fundiária no Brasil: uma comparação internacional e um estudo de caso. 2000. $254 \mathrm{f}$. Tese (Doutorado em Economia) - Instituto de Economia da Universidade Estadual de Campinas - IE/UNICAMP, Campinas, 2000. Disponível em: http://repositorio.unicamp.br/jspui/handle/REPOSIP/285576

GUILDING, C.; CRAVENS, K. S.; TAYLES, M. An international comparison of strategic management accounting practices. Management Accounting Research, v. 11, n. 1, p. 113-135, mar. 2000. https://doi.org/10.1006/mare.1999.0120

HANSEN, D. R.; MOWEN, M. M. Gestão de custos: contabilidade e controle. 2. ed. São Paulo: Cengage Learning, 2010.

KAJÜTER, P.; KULMALA, H. I. Open-book accounting in networks: potential achievements and reasons for failures. Management Accounting Research, v. 16, n. 2, p. 179-204, jun. 2005.

http://dx.doi.org/10.1016/j.mar.2005.01.003

KOURTI, I. Why should we collaborate? Exploring partners' interactions in the psychosocial spaces of an inter-organizational collaboration. Scandinavian Journal of Management, v. 33, n. 2, p. 93-101, jun. 2017. https://doi.org/10.1016/j.scaman.2017.03.002

KOTLER, P.; ARMSTRONG, G. Princípios de marketing. 7. ed. Rio de Janeiro: LTC, 1999.

KULMALA, H. I. Developing cost management in customer-supplier relationships: three case studies. Journal of Purchasing and Supply Management, v. 10, n. 2, p. 65-77, 2004.

https://doi.org/10.1016/j.pursup.2004.02.003

KULMALA, H. I. Open-book accounting in networks. The Finnish Journal of Business Economics, v. 52, n. 2, p.157-177, 2002. Disponível em: http://ta.lib.aalto.fi/2002/2/lta_2002_02_a2.pdf. Acesso em: 10 ago. 2017.

KULMALA, H. I.; PARANKO, J.; UUSI-RAUVA, E. The role of cost management in network relationships. International Journal of Production Economics, v. 79, p. 33-43, 2002. https://doi.org/10.1016/S09255273(00)00061-X

KUMRA, R.; AGNDAL, H.; NILSSON, U. Open book practices in buyer-supplier relationships in India. Journal of Business \& Industrial Marketing, v. 27, n. 3, p. 196-210, 2012. http://dx.doi.org/10.1108/08858621211207225

LATUSEK, D.; VLAAR, P. W. L. Uncertainty in interorganizational collaboration and the dynamics of trust: a qualitative study. European Management Journal, v. 26, ed. 1, p. 12-27, set. 2018.

https://doi.org/10.1016/j.emj.2017.10.003

MARTINS, G. de A. Estudo de Caso: uma estratégia de pesquisa. 2. ed. São Paulo: Atlas, 2008.

NYAGA, G. N.; WHIPPLE, J. M.; LYNCH, D. F. Examining supply chain relationships: do buyer and supplier perspectives on collaborative relationships differ? Journal of Operations Management, v. 28, n. 2, p. 101114, mar. 2010. https://doi.org/10.1016/j.jom.2009.07.005

PASWAN, A.K.; HIRUNYAWIPADA, T.; IYER, P. Opportunism, governance structure and relational norms: an interactive perspective. Journal of Business Research, v. 77, ago. 2017.

https://doi.org/10.1016/j.jbusres.2017.04.012

PECI, A. Emergência e proliferação de redes organizacionais: marcando mudanças no mundo de negócios. Revista de Administração Pública, Rio de Janeiro, v. 33, n. 6, p. 7-24, mar. 1999. Disponível em: http://bibliotecadigital.fgv.br/ojs/index.php/rap/article/view/7596. Acesso em: 21 jun. 2018.

PORTER, M. E. Estratégia competitiva: técnicas para análise das indústrias e da concorrência. 7. ed. Rio de Janeiro: Campus, 1991.

PORTER, M. E. Vantagem competitiva: criando e sustentando um desempenho superior. 15. ed. Rio de Janeiro: Campus, 1989. 
ROCHA, W.; BORINELLI, M. L. Análise Estratégica de Cadeia de Valor: um estudo exploratório do segmento indústria-varejo. Revista Contemporânea de Contabilidade, v. 1, n. 7, p. 145-165, jan./jun. 2007. Disponível em: https://periodicos.ufsc.br/index.php/contabilidade/article/view/835/656

SADEGHI, L.; JOKAR, I. Identification and classification of open book accounting dimensions by considering inter-organizational cost management: a case study of petrochemical companies listed in Tehran Stock Exchange. Management Science Letters, v. 4, n. 2, p. 295-302, 2014.

http://dx.doi.org/10.5267/j.msl.2013.12.025

SANTOS, R. P. D.; ROCHA, W. Contabilidade focada nos concorrentes: um estudo exploratório no setor de agronegócios. Sociedade, Contabilidade e Gestão, v. 6, n. 1, p. 18-38, 2011. Disponível em: http://www.spell.org.br/documentos/ver/33919/competitor-focused-accounting--an-exploratory-study-in-theagribusiness-industry-li/en. Acesso em: 20/02/2018.

SHANK, J. K.; GOVINDARAJAN, V. A revolução dos custos: como reinventar e redefinir sua estratégia de custos para vencer em mercados crescentemente competitivos. 2. ed. Rio de Janeiro: Campus, 1997.

SOUZA, B. C.; ROCHA, W. Fatores condicionantes da gestão de custos interorganizacionais. In: Congresso de Controladoria e Contabilidade da USP, 8., 2008. Anais... Congresso USP, São Paulo, SP, Brasil, 2008.

SOUZA, B. C.; ROCHA, W. Gestão de custos interorganizacionais: ações coordenadas entre clientes e fornecedores para otimizar resultados. São Paulo: Atlas, 2009.

SOUZA, M. A.; HEINEN, A. C. Práticas de Gestão Estratégica de Custos: uma análise de estudos empíricos internacionais. Journal of Accounting, Management and Governance, Brasília, v. 15, n. 2, p. 23-40, mai./ago. 2012. Disponível em: https://www.cgg-amg.unb.br/index.php/contabil/article/view/397/pdf. Acesso em: 18 ago. 2017.

VILLENA, V. H.; REVILLA, E.; CHOI, T. Y. The dark side of buyer-supplier relationships: a social capital perspective. Journal of Operations Management, v. 29, n. 6, p. 561-576, set. 2011.

https://doi.org/10.1016/j.jom.2010.09.001

WAGNER, S. M.; BODE, C. Supplier relationship-specific investments and the role of safeguards for supplier innovation sharing. Journal of Operations Management, v. 32, n. 3, p. 65-78, mar. 2014.

https://doi.org/10.1016/j.jom.2013.11.001

WEI, Y.; XU, C.; HU, Q. Transformation of optimization problems in revenue management, queueing system, and supply chain management. International Journal Production Economics, v. 146, n. 1, p. 588-597, dez. 2013. https://doi.org/10.1016/j.jpe.2013.08.007

WILLIAMSON, O. E. The Mechanisms of Governance. New York: Oxford University Press, 1996.

WILLIAMSON, O. E. Transaction cost economics and organization theory. Industrial and Corporate Change. Oxford University Press, v. 2, n. 2, p. 107-156, 1993. http://dx.doi.org/10.1093/icc/2.2.107

WILLIAMSON, O. E. Comparative economic organization: the analysis of discrete structural alternatives. Administrative Science Quarterly, v. 36, n. 2, p. 269-296, 1991. http://dx.doi.org/10.2307/2393356

WILLIAMSON, O. E. The economic institutions of capitalism: firms, markets, relational contracting. London: Macmillan Free Press, 1985.

WINDOLPH, M.; MOELLER, K. Open-book accounting: reason for failure of inter-firm cooperation? Management Accounting Research, v. 23, n. 1, p.47-60, 2012. https://doi.org/10.1016/j.mar.2011.07.001

YIN, R. K. Estudo de Caso: planejamento e métodos. 4. ed. Porto Alegre: Bookman, 2010. (Trad. Ana Thorell).

ZHANG, Q.; et al. Untangling the safeguarding and coordinating functions of contracts: direct and contingent value in China. Journal of Business Research, v. 78, p. 184-192, 2017.

https://doi.org/10.1016/j.jbusres.2016.12.014

ZIBETTI, D. W.; BARROSO, L. A. (Org.). Agroindústria: uma análise no contexto socioeconômico e jurídico brasileiro. 1. ed. São Paulo: Livraria e Editora Universitária de Direito, 2009. 
ZYLBERSZTAJN, D.; SZTAJN, R. (Org.). Direito \& Economia: análise econômica do direito e das organizações. Rio de Janeiro: Elsevier, 2005.

ZYLBERSZTAJN, D. Estruturas de governança e coordenação do agribusiness: uma aplicação da nova economia das instituições. 1995. 239 f. Tese de Livre Docência. Departamento de Administração, Faculdade de Economia e Administração e Contabilidade, Universidade de São Paulo, São Paulo, 1995. Disponível em: http://www.erudito.fea.usp.br/PortalFEA/Repositorio/616/Documentos/Tese_Livre_Docencia_DZ.pdf

\section{NOTAS}

\section{AGRADECIMENTOS}

Gostaríamos de agradecer à empresa que aceitou participar da pesquisa e à CAPES - Coordenação de Aperfeiçoamento de Pessoal de Nível Superior pela concessão de bolsa de mestrado a um dos autores.

\section{CONTRIBUIÇÃO DE AUTORIA}

Concepção e elaboração do manuscrito: A. M. Cardoso, L. C. F. A. Fehr, R. P. Gonzaga, S. L. Duarte

Coleta de dados: A. M. Cardoso

Análise de dados: A. M. Cardoso, L. C. F. A. Fehr, R. P. Gonzaga, S. L. Duarte

Discussão dos resultados: A. M. Cardoso, L. C. F. A. Fehr, R. P. Gonzaga, S. L. Duarte

Revisão e aprovação: A. M. Cardoso, L. C. F. A. Fehr, R. P. Gonzaga, S. L. Duarte

\section{CONJUNTO DE DADOS DE PESQUISA}

O conjunto de dados que dá suporte aos resultados deste estudo não está disponível publicamente.

\section{FINANCIAMENTO}

Houve financiamento na forma de bolsa de mestrado para um dos autores, Anderson Martins Cardoso, cujo órgão de fomento foi a CAPES. Número do processo: 1718977. "O presente trabalho foi realizado com apoio da Coordenação de Aperfeiçoamento de Pessoal de Nível Superior - Brasil (CAPES) - Código de Financiamento 001".

\section{CONSENTIMENTO DE USO DE IMAGEM}

Não se aplica.

\section{APROVAÇÃO DE COMITÊ DE ÉTICA EM PESQUISA}

Aprovação do Comitê de Ética em Pesquisa da Universidade Federal de Uberlândia. Número do processo CAAE: 91725518.3 .0000 .5152 , de 29/09/2018.

\section{CONFLITO DE INTERESSES}

Não se aplica.

\section{LICENÇA DE USO}

Os Direitos Autorais para artigos publicados neste periódico são do autor, com direitos de primeira publicação para a Revista. Em virtude de aparecerem nesta Revista de acesso público, os artigos são de uso gratuito, com atribuições próprias, em aplicações educacionais, de exercício profissional e para gestão pública. A Revista adotou a licença Creative Commons Atribuição 4.0 Internacional - CC BY NC ND. Esta licença permite acessar, baixar (download), copiar, imprimir, compartilhar, reutilizar e distribuir os artigos desde que com a citação da fonte, atribuindo os devidos créditos de autoria. Nesses casos, nenhuma permissão é necessária por parte dos autores ou dos editores. Autores têm autorização para assumir contratos adicionais separadamente, para distribuição não-exclusiva da versão do trabalho publicada nesta revista (ex.: publicar em repositório institucional ou um capítulo de livro).

\section{PUBLISHER}

Universidade Federal de Santa Catarina. Curso de Ciências Contábeis e Programa de Pós-graduação em Contabilidade. Publicação no Portal de Periódicos UFSC. As ideias expressadas neste artigo são de responsabilidade de seus autores, não representando, necessariamente, a opinião dos editores ou da universidade.

\section{EDITORES}

Carlos Eduardo Facin Lavarda e Suliani Rover

\section{HISTÓRICO}

Recebido em: 01/04/2019 - Revisado por pares em: 04/05/2020 - Reformulado em: 03/06/2020 Recomendado para publicação em: 10/07/2020 - Publicado em: 30/07/2020 